\title{
WestVirginiaUniversity
}

THE RESEARCH REPOSITORY @ WVU

Graduate Theses, Dissertations, and Problem Reports

2013

\section{Effect of Delmopinol Hydrochloride on Endodontic Biofilm}

Gabriel M. Holley

West Virginia University

Follow this and additional works at: https://researchrepository.wvu.edu/etd

\section{Recommended Citation}

Holley, Gabriel M., "Effect of Delmopinol Hydrochloride on Endodontic Biofilm" (2013). Graduate Theses, Dissertations, and Problem Reports. 3610.

https://researchrepository.wvu.edu/etd/3610

This Thesis is protected by copyright and/or related rights. It has been brought to you by the The Research Repository @ WVU with permission from the rights-holder(s). You are free to use this Thesis in any way that is permitted by the copyright and related rights legislation that applies to your use. For other uses you must obtain permission from the rights-holder(s) directly, unless additional rights are indicated by a Creative Commons license in the record and/ or on the work itself. This Thesis has been accepted for inclusion in WVU Graduate Theses, Dissertations, and Problem Reports collection by an authorized administrator of The Research Repository @ WVU. For more information, please contact researchrepository@mail.wvu.edu. 


\title{
Effect of Delmopinol Hydrochloride on Endodontic Biofilm.
}

\author{
Gabriel M. Holley, DDS \\ Thesis Submitted to the \\ School of Dentistry \\ At West Virginia University \\ in partial fulfillment of the requirements \\ for the degree of \\ Master of Science \\ In \\ Endodontics
}

John G. Thomas, PhD, Chair

Anthony T. Borgia, DDS, MHA

Michael Bagby, DDS, PhD

Department of Endodontics

Morgantown, West Virginia

2013

Keywords:

Biofilm, Delmopinol Hydrochloride, Irrigation 


\section{$\underline{\text { Abstract }}$ \\ Effect of Delmopinol Hydrochloride on Endodontic Biofilm}

\section{Gabriel M Holley, DDS}

Background: The ideal goal of endodontic therapy is to decrease the microbial load within the root canal system followed by the placement of a hermetic seal of the apical portion of the root. Sodium hypochlorite $(\mathrm{NaOCl})$ has long been considered the gold standard for disinfecting root canals, but, the presence of a persistent intraradicular biofilm in properly cleaned and shaped canals has led to the need of development for adjunct irrigant targeting these complex structures. Objectives: The purpose of this study was to compare the effects on the biofilm of $\mathrm{NaOCl}$ and delmopinol hydrochloride (DH), a new FDA approved oral rinse, on multiple species biofilms. Methods: Preliminary data was collected with zones of inhibition on Candida albicans, Staphylococcus aureus and Pseudomonas aeruginosa grown on Mueller-Hinton vs 30\% Poloxamer (biofilm phenotype) plates incubated at $37 \mathrm{C}$ for 24 hours. The effect was then studied using a Calgary Bioflm Device with crystal violet staining (CV), scanning electron microscope imaging (SEM) and sonication with Mueller-Hinton plating. Results: The data showed that delmopinol hydrochloride does not possess the strong antimicrobial properties that sodium hypochlorite does. However, delmopinol hydrochloride did possess antibiofilm capabilities, on all organisms that remained, even at diluted concentrations. Conclusion: Delmopinol hydrochloride is not an irrigant to replace sodium hypochlorite, but could be used as an adjunct in the final steps of irrigation to reduce biofilm colonization. 


\section{$\underline{\text { Dedication }}$}

To my beautiful wife, Amy. We have come this far, do not leave me now... 


\section{Acknowledgements}

I would like to thank Dr. Anthony T. Borgia and Dr. C. Russell Jackson for forever changed my life, and for believing in a kid who sometimes did not believe in himself.

Dr. Anthony T. Borgia, your mentorship has been above and beyond. I will forever hear your words of wisdom when encountered with difficult situations. I will miss our morning coffee sessions, history lessons, and the friendship that has grown over the past two years. You are a great educator, mentor, confidant, and man. Thank you.

Dr. C. Russell Jackson, I will never forget the day I walked in your office and said "I think I'm in trouble." You took one look at me and said "By the way you're sweating, I'm sure you are." Thank you for encouraging me to pursue hobbies outside of dentistry and the life lessons you have taught me. By observing you, I have learned a lot on how to treat people, not just endodontically, but genuinely. Thank you.

Dr. John G. Thomas, thank you for being you. The lessons that you have provided on life outside of this institution are invaluable. I have enjoyed our discussions on microbes, biofilms, skiing, Vermont, and so much more. My wife and I are going to steal your family newsletter idea. I hope you do not mind. Thank you.

Dr. Michael Bagby, thank you for being the man that does everything. Your guidance throughout dental school and my residency have been irreplaceable. You kept me on track when I began to waiver, and for that I am thankful. Thank you.

Dr. Amanda Ammer, thank you for your time teaching me the ins and outs of the Carl Zeiss microscope. I assure you, everything was still working when I left. Thank you.

Dr. Gerald Hobbs, thank you for your work with my statistics and for taking the time to explain them to a confused dentist. I hope you catch some ballgames this summer. Thank you.

Jeremy Hardinger, thank you for the fantastic SEM images and for answering my 50 emails.

Dr. Nathaniel Nicholson and Dr. Khaled Seifelnasr, for only being together for less than a year, you act like an old married couple. One of these days, you will have the special relationship that Dustin and I share. I just hope you do not need a canceled flight out of Boston to realize it.

Dr. Dustin Reynolds, I sit back and think about them good old days, the way we was raised in our Southern ways... Carl Zeus, Coke heavy, memories. The past two years have gone by so quickly, and honestly, I'm surprised you made it. I could not have asked for a better co-resident. I hope the ones that follow are as lucky. Too soon, we will be sitting on a river bank reminiscing. 
Dr. Tuyen Pham and Dr. Patrick Petley, the first year of residency was very interesting. Thank you for your advice on cases and allowing Dustin and I to use .04 tapers. I hope we keep in touch.

Renee Cooper, thank you for all your hard work within the Endodontic Department. You stepped up when times were tough; however, your supply store runs were lacking the elephant treats I requested.

Gina White, thank you for tolerating Dustin and I's shenanigans. You are an amazing person who dedicates a lot of time and energy to this department, and it is greatly appreciated.

Donna Butler, I know that I am your favorite resident to ever pass through; you do not actually have to say it. A position in my office will always be open. Thank you.

Ashley, I know you came in the game late, but you have been clutch. I have enjoyed our time together and wish you well on the pursuit of a dental career. Thank you

Charalene Haynes, thank you for all your hard work during my first year of residency, you always lightened the mood with your humor. I hope you are enjoying Connecticut.

Tammy Ord, thank you for making sure my fees were always entered and locating the emergency students for us. Enjoy your morning eggs. 


\section{Table of Contents}

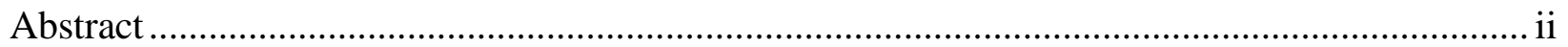

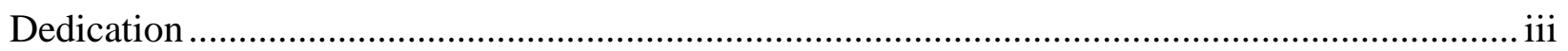

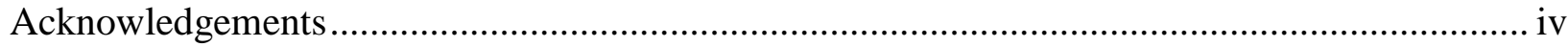

Table of Contents ....................................................................................................... vi

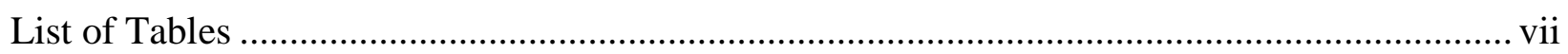

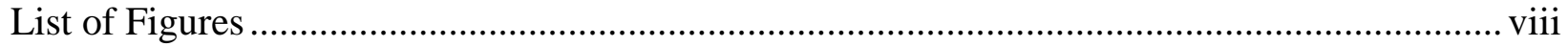

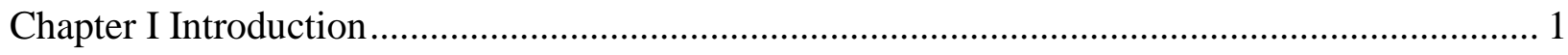

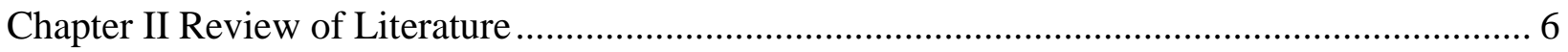

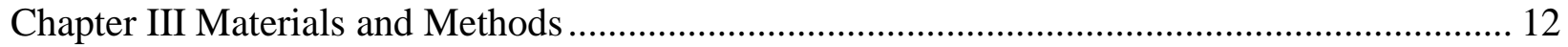

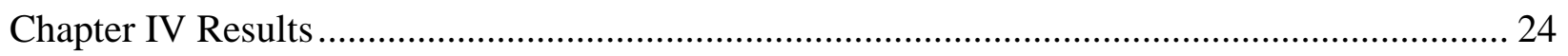

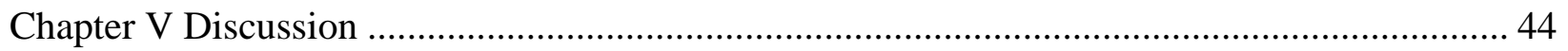

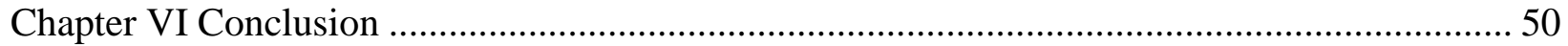

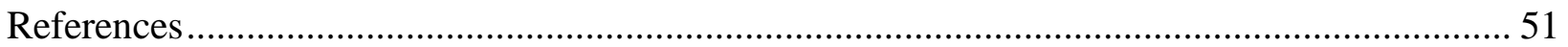




\section{$\underline{\text { List of Tables }}$}

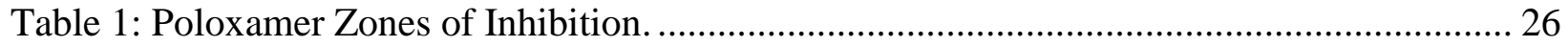

Table 2: Mueller Hinton Zones of Inhibition...................................................................... 28

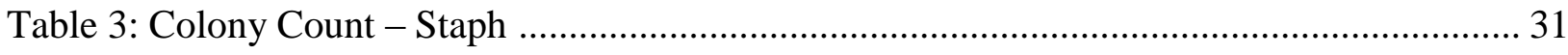

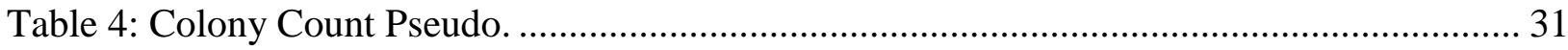

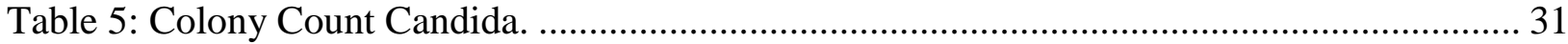




\section{$\underline{\text { List of Figures }}$}

Figure 1 Cell wall of gram positive and negative prokaryotes. ................................................. 13

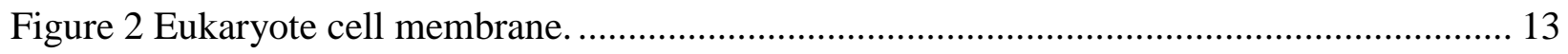

Figure 3 Laboratory Photograph....................................................................................... 18

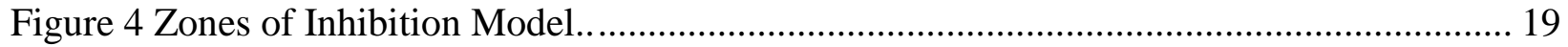

Figure 5 Calgary Biofilm Device......................................................................................... 20

Figure 6 Layout of Wells for Calgary Biofilm Device............................................................. 21

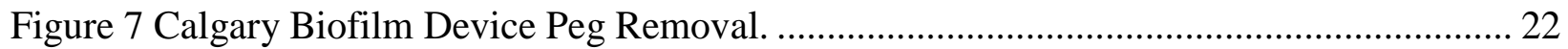

Figure 8 Biofilm Coverage, Crystal Violet Stained Peg......................................................... 23

Figure 9 Poloxamer Zones of Inhibition.............................................................................. 27

Figure 10 Mueller Hinton Zones of Inhibition. .................................................................. 29

Figure 11 Staph Biofilm Coverage using CBD. .................................................................. 30

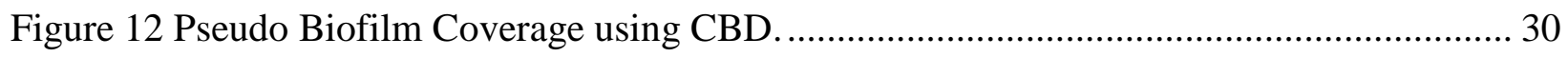

Figure 13 Candida Biofilm Coverage using CBD. ................................................................. 30

Figure 14 Template for SEM Images.............................................................................. 32

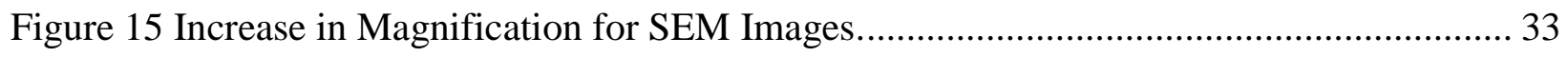

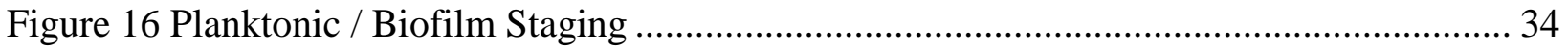

Figure 17 Structural Biofilm Stage III Example...................................................................... 34

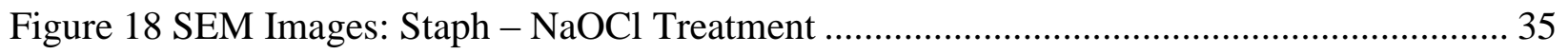

Figure 19 SEM Images: Staph - DH Treatment .......................................................................... 36

Figure 20 SEM Images: Staph - Saline Treatment................................................................ 37

Figure 21 SEM Images: Pseudo - $\mathrm{NaOCl}$ Treatment ................................................................... 38

Figure 22 SEM Images: Pseudo - DH Treatment …………………………………............ 39

Figure 23 SEM Images: Pseudo - Saline Treatment ………..................................................... 40

Figure 24 SEM Images: Candida - NaOCl Treatment ……………........................................... 41

Figure 25 SEM Images: Candida - DH Treatment................................................................... 42

Figure 26 SEM Images: Candida - Saline Treatment ............................................................... 43 


\section{Chapter I}

\section{$\underline{\text { Introduction }}$}

The goal of endodontics is the reduction of microorganisms within the root canal system and inhibition of bacterial recontamination by adequately sealing the apical and coronal portions of the root. (Schilder 1967) It is well known that mechanical instrumentation alone is not sufficient to eliminate all bacteria present within the intricacies of the root canal system. (Bystrom and Sundqvist 1981) Irrigation of the root canal, therefore, has long been used as an adjunct in the process known as chemomechanical debridement of the root canal system. The mechanical instrumentation of the root canal then, facilitates delivery of the irrigation solution to the apical portion of the root canal, increasing the operator's ability to effectively reduce the biovolume, while providing the required conditions for proper obturation of the root canal system. Many techniques of instrumentation, irrigation and obturation have been debated over the years, and although research has been conducted to discover a new irrigant, sodium hypochlorite has long remained the irrigant of choice.

Sodium hypochlorite $(\mathrm{NaOCl})$ has historically been the standard irrigant used in combination with instrumentation for chemomechanical debridement of the root canal system.

(Walker 1936, Grossman and Meiman 1941, Senia 1971) Numerous concentrations of $\mathrm{NaOCl}$ have been studied to determine the concentration that allows for the most bactericidal capability, while at the same time limiting the risk of tissue necrosis if accidental extrusion into the periapical region occurs. (Zehnder 2006) Although researchers continue to debate the concentration that is most effective, the risks of tissue damage still remain. 
The search for a new, ideal endodontic irrigant has continued. The effects of agents such as EDTA, MTAD, QMIX and chlorhexidine have been studied and compared to $\mathrm{NaOCl}$, but so far, none have surpassed its debridement capabilities. Recently, avocation for the combination of $\mathrm{NaOCl}$, EDTA and chlorhexidine, as well as ultrasonic agitation of these various solutions, has led to research to determine the best protocol for decreasing the biovolume. (Krishnamurthy 2010, Beus 2012)

The endodontic literature has recently began focusing on investigating the role of biofilms in endodontic failures. Investigators have attempted to understand the role that they play in endodontic therapy, as well as, the most effective ways to remove them. While mechanical debridement is the method of choice, the intricacies of the root canal system do not allow for adequate debridement utilizing this method alone.

Delmopinol hydrochloride, currently marketed as PerioShield ${ }^{\mathrm{TM}}$, has been used in Periodontics as an antibiofilm mouth rinse. Delmopinol hydrochloride decreases dental plaque's ability to adhere to teeth, reducing biofilm formation and at the same time penetrates already established plaque to allow for easier mechanical debridement. (Simonsson 2007) Destruction of biofilms is a necessity in successfully treating bacteria related diseases, and any agent found to contribute to this goal would be of value in endodontic treatment. 


\section{Statement of the Problem}

Is delmopinol hydrochloride a more effective irrigant against biofilms within the root canal system compared to sodium hypochlorite?

\section{Significance of the Problem}

The most commonly used irrigant today during endodontic therapy is sodium hypochlorite. Biofilms within the root canal system of teeth have been attributed to a decrease in success of endodontic therapy. Previous studies have been conducted to determine the effects of $\mathrm{NaOCl}$, EDTA and chlorhexidine on the biofilm with $\mathrm{NaOCl}$ being found to be the most effective. Complete eradication of microorganisms has not yet been observed.

Delmopinol hydrochloride is currently marketed as PerioShield ${ }^{\mathrm{TM}}$, a mouth rinse found to be effective against disrupting periodontal biofilm. Since delmopinol hydrochloride was created specifically for the dissolution of biofilms in the oral cavity, addressing the question of its effect against biofilms found within the root canal system might be of great value in endodontics. If delmopinol hydrochloride is effective against endodontic biofilms, it could possibly be used in combination with sodium hypochlorite for achieving an enhanced level of anti-microbial action within the root canal system. 


\section{Null Hypothesis}

Delmopinol hydrochloride is not as effective on an endodontic biofilm when compared to sodium hypochlorite.

\section{$\underline{\text { Assumptions }}$}

1) Sodium hypochlorite is the most commonly used irrigant in endodontics.

2) It is commonly accepted that instrumentation alone will not adequately remove organisms within the root canal system.

3) The use of sodium hypochlorite alone does not eradicate all biofilm.

4) Research has shown that adjuncts to the two common practices of instrumentation and sodium hypochlorite irrigation are required for a decrease in the number of residual organisms present within the root canal system.

\section{$\underline{\text { Limitations }}$}

1) This is an in vitro experiment to simulate an in vivo process.

2) The hydroxyapatite pegs in this investigation are designed to be used more appropriately in periodontal studies.

3) Internal anatomy of teeth varies compared to the hydroxyapatite pegs.

4) Methodology is tedious and is at risk for contamination.

5) This is a macroscopic assay relying heavily on visualization.

6) Organisms chosen were selected based on utility, expense, and the fact that there is experience growing biofilm and other antibiofilm evaluations. 
7) There is a large repository of SEM photomicrographs of biofilms of the 3 organisms forming monospecies or multispecies biofilms.

\section{$\underline{\text { Delimitations }}$}

1) All irrigating solutions were compared using the same standards throughout the experiment.

2) All portions of the experiment were performed by one investigator.

3) Outside wells of the Calgary Biofilm Device Microtider tray were not used to reduce the potential for evaporation. 


\section{Chapter II}

\section{$\underline{\text { Review of Literature }}$}

Pulp necrosis is the loss of vitality of the pulp of a tooth, which in turn may lead to periapical bone destruction. According to Kakehashi et al, pulp necrosis occurs when bacteria are present within pulp tissues, but not when the pulp is manipulated in a sterile environment. (Kakehashi 1965) While the goal of endodontic therapy is sterilization of the root canal system followed by complete obturation to prevent recontamination of the space, complete sterilization is virtually impossible to achieve within the intricate workings of all parts of the root canal system. Alternatively, a reduction in the bioload to levels that are insignificant to elicit apical infection is a targeted goal. In order to achieve this goal in the reduction of the bioload, proper cleaning and shaping techniques must be employed; however, the mechanical debridement of the root canal system alone is not enough. (Bystrom and Sundqvist 1981) The intricacies of the root canal system do not allow for all surfaces to be contacted during the cleaning and shaping of the canal, leaving behind areas of bacteria that have been undisturbed. (Vertucci 1984) Irrigants have been used in endodontics to help reduce the biovolume within those areas unable to be cleaned with traditional filing and reaming alone, and to assist in the removal of the debris formed and accumulated during the cleaning and shaping process.

The development of rotary instrumentation has led to an increased ability of mechanically debriding the canals. The use of rotary instrumentation in combination with sodium hypochlorite decreases the biovolume, but has not been able to render canals completely sterilized. (Shuping and Trope 2000) Currently, advancements in development of new rotary instrumentation are being focused on increasing the surface area of the files to better clean and shape canals. (Peters 
2004) Instruments such as the self-adjusting file are being investigated as a way to not only maintain and contact the intricate anatomy of the root canal system, but also to ensure physical contact with all surfaces that potentially harbor microorganisms and organic debris while introducing a new method of chemomechanical debridement. (Metzger 2010) It is hoped that the combination of improved instrumentation techniques along with the use of effective irrigation solutions will result in complete sterilization of the root canal system and a concomitant increase in clinical success.

The ideal irrigant should have the ability to reduce the bioload, solubilize necrotic tissue, be nontoxic to vital, healthy tissues if extruded from the root canal system, act as a lubricant, remove the smear layer and disinfect areas untouched by mechanical debridement. (Goldman 1981, Hulsmann 2003) Practitioners have used multiple and varied solutions in attempt to fulfill these requirements. Some irrigants possess more of the necessary qualities than others, but none of the irrigants commercially available today fulfill the description of the ideal irrigant.

Currently, the acknowledged endodontic irrigant of choice is sodium hypochlorite $(\mathrm{NaOCl}) . \mathrm{NaOCl}$ has long been used for the debridement and disinfection of wounds received by soldiers in war. (Dakin 1915) Its use has been recommended for the cleaning of canals of pulpless teeth, as well as an effective pulpal tissue solvent. (Walker 1936, Grossman and Meiman 1941, Senia 1971, Hand 1978) The antimicrobial and necrotic tissue dissolving properties of $\mathrm{NaOCl}$ remain the standard that is set for all others to be evaluated against; however, $\mathrm{NaOCl}$ is a known cytotoxin and irritant to healthy tissue. (Spangberg 1973) This cytotoxic effect has led to a debate about the concentration of $\mathrm{NaOCl}$ that is most effective against bacteria, while being clinically acceptable in reducing the risks if extruded from the root canal system into the periapical region. (Baumgartner 1992) Several instances of $\mathrm{NaOCl}$ 
accidents have been documented, resulting in harm to the same patients that are undergoing treatment. (Ehrich 1993, Becking 1991, Hulsmann 2000) Despite all of the risks associated with the use of $\mathrm{NaOCl}$, there is general agreement that it continues to be the irrigant of choice in achieving a reduction in bioload in root canals. Several attempts have been made to replace $\mathrm{NaOCl}$ as the irrigant of choice with a more biocompatible, yet still effective antimicrobial, solution. Solutions such as EDTA, chlorhexidine, MTAD, and QMix have been investigated as potential replacements.

After mechanical debridement and use of $\mathrm{NaOCl}$ as an irrigant, a smear layer is produced on the walls of the root canal system. (McComb and Smith 1975) This smear layer blocks dentinal tubules, leaving behind remnants of pulpal debris, bacteria, and odontoblastic processes, thereby, reducing or inhibiting the sealing ability that is the goal of the obturation. (McComb and Smith 1975, Clarke-Holke 2003) $\mathrm{NaOCl}$ alone is not sufficient to adequately remove all debris that has accumulated within the dentinal tubules because the composition of the debris contains mostly inorganic material. (Lester and Boyde 1977) However, ethylenediaminetetraacetic acid (EDTA) at a $17 \%$ concentration is capable of removing this smear layer that is left behind. (McComb and Smith 1975) It has been further demonstrated that the most efficient way to eliminate the smear layer is a combination of both $\mathrm{NaOCl}$ and EDTA. (Ciuucchi and Khettabi 1989) This allows for the resulting walls of the root canal system to be rendered smoother and cleaner. (Baumgartner and Mader 1987) By eliminating and cleaning the dentinal tubule debris, endodontic sealer is thought to result in a better seal at the interface of the walls of the root canal. (Oksan et al 1993) Tubular penetration of the EDTA increases the surface area available for the root canal cement to adequately seal the root canal system and prevent leakage. (White et al 1984) The debate is ongoing as to whether or not it is amenable to 
remove the smear layer, and the role it plays in the long term success rates of root canal therapy. (Violich 2010)

Chlorhexidine's (CHX) antimicrobial capabilities have been thoroughly studied when compared to $\mathrm{NaOCl}$ to find a comparable irrigant with less cytotoxic risk. $\mathrm{CHX}$ is a nonirritating solution that has antimicrobial capabilities comparable to $\mathrm{NaOCl}$ against some microorganisms, including Enterococcus faecalis. (Vianna 2004) CHX also possess potential for the disruption of biofilms formed within the root canal system. (Ordinola-Zapata 2012) One of the most significant disadvantages of replacing $\mathrm{NaOCl}$ with $\mathrm{CHX}$ is the inability of $\mathrm{CHX}$ to dissolve organic matter, a key and highly desireable component to the ideal root canal system irrigant. (Mohammadi 2009) $\mathrm{CHX}$ is commonly used as an adjunct to $\mathrm{NaOCl}$, but, when mixed with and used in combination with $\mathrm{NaOCl}$ a brown/red precipitate forms called parachloroanaline. (Zehnder 2006, Basrani 2007) Debate as to the carcinogenicity of the precipitate is still under investigation, but it is known that the resulting precipitate formed is difficult to remove from the walls of the root canal system. Procedures have been discussed in the endodontic literature to avoid forming the precipitate which includes an irrigation step between using the $\mathrm{NaOCl}$ and the CHX with EDTA or alcohol. (Krishnamurthy 2010)

Despite the antimicrobial and irrigating effectiveness of both $\mathrm{NaOCl}$ and EDTA in the root canal system and even after, proper cleaning and shaping along with proper obturation of all the canals, some level of microorganisms remain behind with the possible result being failure of the root canal therapy. (Siqueira Jr 2001) Recent studies have discussed the presence of one or more biofilms within root canal systems, making the complete debridement and reduction of the bioload more difficult than was previously realized. (Chavez de Paz 2007, Carr 2009) A biofilm consists of microorganisms embedded in a macropolysaccharide matrix, a complicated and 
essential component, which allows for greater impenetrability of anti-microbial agents and increases survival in a hostile environment. (Costerton 1999, Stoodley 2002) By forming this conglomerate embedded in an extracelluar matrix, microorganisms, typically found in their planktonic state, become less susceptible to antibacterial techniques currently used in medicine and dentistry. (Stewart and Costerton 2001, Nair 1987, Costerton 2003, Wilson 1996)

The presence of a biofilm within the root canal system is a topic of relatively recent concentration. One such clinical example is the examination of endodontic biofilms by Carr which reviewed a failed molar endodontic retreatment. The investigators found that a biofilm was present in a resected portion of a mesial root of a mandibular molar. They concluded that despite the harsh conditions, microorganisms within a biofilm community can survive with no obvious source of nutrients. Additionally, biofilms were seen to be diverse, holding multiple species of bacteria. (Carr et al 2009) Tronstad conducted a study to evaluate the presence of biofilms in persistent periradicular granulomas and concluded that biofilms aide in the resistance to the body's ability to resolve a lesion. (Tronstad et al 1990) This combination of diversity and substantivity decreases antimicrobial effectiveness of the current irrigants used in endodontics. (Clegg 2006) Several recent studies have been conducted to determine the effect that the root canal irrigants have on the biofilms, and that search continues, with no ideal agents as yet identified.

Delmopinol hydrochloride is an oral antiseptic rinse that has been found to demonstrate a bactericidal effect on biofilm formation. (Burgemeister 2001) The patent is currently held by Sinclair Pharmaceuticals LTD of Surrey, Great Britain. (Lane and Sjodin 2008) It is currently marketed as PerioShield ${ }^{\mathrm{TM}}$ by GUM Products ${ }^{\circledR}$. It is considered an alternative mouth rinse to chlorhexidine digluconate. Delmopinol has been proven to prevent and greatly hinder the 
formation of biofilms on various surfaces. The intention of the developers of delmopinol is to now introduce this chemical into several areas of both health care and industrial capacities. Delmopinol has not as yet been considered as an alternative for endodontic irrigation.

Currently, delmopinol hydrochloride is being used as an antiplaque oral mouth rinse in $0.12 \%$ concentration. In a study performed by Klinge, delmopinol hydrochloride was shown to inhibit the formation of plaque on the buccal surfaces of teeth by $83 \%$ when compared to no treatment. (Klinge 1996) In 2007, Simonsson studied and demonstrated the its success by0 showing the ability of delmopinol hydrochloride to penetrate an already established plaque formation. (Simonsson 1991) This penetrating ability of delmopinol hydrochloride to penetrate biofilms is accompanied by an increase in efficacy for mechanical debridement of the plaque.

Dental plaque is the most recognized biofilm in dentistry. Delmopinol hydrochloride has shown effectiveness in the inhibition of plaque formation and an increased ability to effectively remove plaque. As previously discussed, a biofilm within the root canal system is a complicated and tenacious collection of microorganisms that can result in a persistent source of infection. (Chavez de Paz 2007) Given delmopinol hydrochloride's clinical history of biofilm reduction, it is logical to investigate the effectiveness of delmopinol hydrochloride against an endodontic biofilm. 


\section{Chapter III}

\section{Materials and Methods}

All steps of the experiment were conducted beneath a Class II Filtech biosafety hood (Figure 3). Proper technique, personal protection and ventilation were used at all times throughout the conduction of the experiment.

\section{$\underline{\text { Solutions }}$}

Saline was used as the positive control irrigant. A concentration of 5.25\% and 2.5\% Sodium Hypochlorite was used as the comparison irrigation solution, hereto referred to as $100 \%$ and 50\%. Delmopinol hydrochloride (PerioShield) in a concentration of .12\% and $.06 \%$ was used as the investigation irrigation solution, hereto referred to as $100 \%$ and $50 \%$.

\section{$\underline{\text { Microorganisms }}$}

The following microorganisms were used to determine effectiveness of the irrigation solutions:

\begin{tabular}{|l|l|l|}
\hline \multicolumn{1}{|c|}{ Staphylococcus aeurus } & \multicolumn{1}{|c|}{ Pseudomonas aeruginosa } & \multicolumn{1}{c|}{ Candida albicans } \\
\hline gram positive, prokaryote & gram negative, prokaryote & $\begin{array}{l}\text { biphasic (yeast and hyphae) } \\
\text { eukaryote }\end{array}$ \\
\hline
\end{tabular}

The three test organisms were selected on differentiation of Gram-positive, Gramnegative and a eukaryote respectively. Gram stain of Staphylococcus aeurus and Pseudomonas aeruginosa show relative size and smaller size compared to eukaryote, and significant differences in structural definition. Those are highlighted in Figure 1 and 2. Candida albicans is 
biphasic, emphasizing its growth both as a yeast phase and hyphal phase, the latter considered potentially more pathogenic. Candida albicans is considered the "universal co-aggregate" and a major building block in transition from planktonic to biofilm architecture.
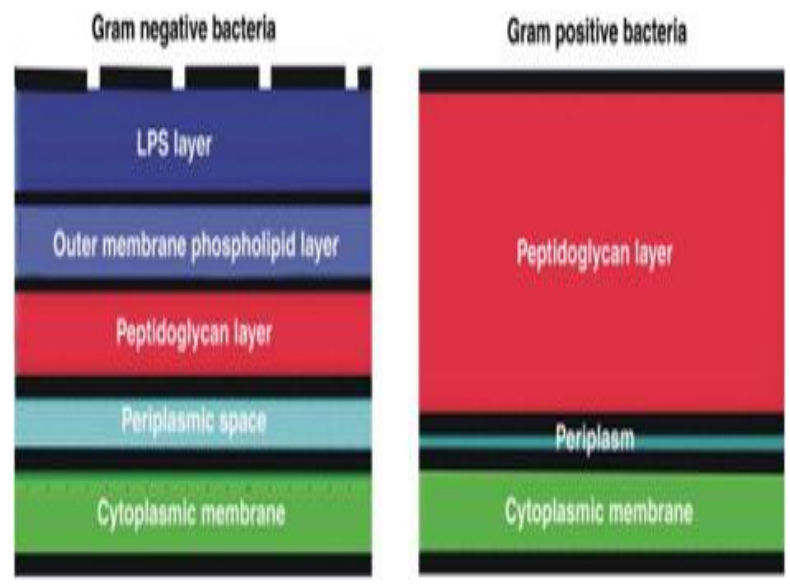

Figure 1 Cell wall of gram positive and gram negative prokaryotes. Courtesy of Dr. John G Thomas

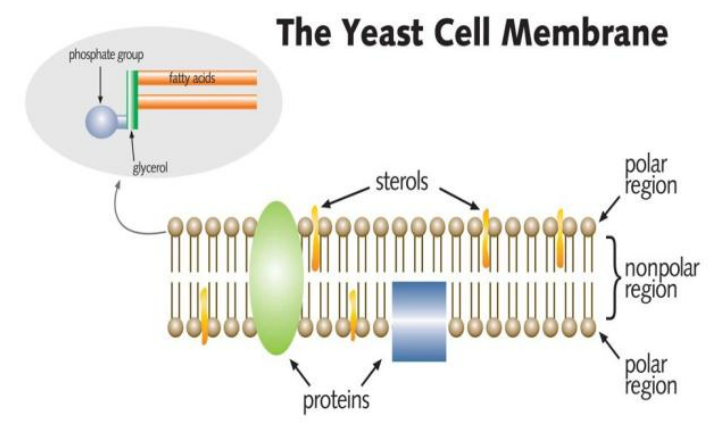

Figure 2 Eukaryote cell membrane. Courtesy of Dr. John G Thomas

All organisms were grown on a blood agar plate and incubated at 37 degrees Celsius for 48 hours. 


\section{Zones of Inhibition (ZOI)}

A 1 microliter $(\mathrm{uL})$ loop of the organism was placed into 5 milliliters $(\mathrm{mL})$ of Tyrptocase Soy Broth (TSB) in a test tube. The test tube was vortexed to ensure mixture. A $250 \mathrm{uL}$ sample of microorganism containing TSB was plated on a freshly poured poloxamer plate. The plates provide a growth medium targeting biofilm formation. The organisms were spread with an Lspreader to ensure even coverage. Blank discs were then soaked in each irrigation solution for

10 second. The excess was wicked with a paper towel and the disc was placed into inoculum of the organism. Antibiotic discs of Vancomycin and Ticarcillin / Clavulanic Acid were used as comparisons to ensure growth of the organisms. A control disc of saline was also placed. All discs were placed to ensure the zones of inhibition would not overlap (Figure 4). The plates were then placed into an incubator at 37 degrees Celsius for 24 hours. The plates were removed and the zones of inhibition were recorded for each solution using a Marathon Electronic Digital Caliper mechanical micrometer.

This experiment was repeated on a Mueller Hinton plate, a medium targeting planktonic growth, with blank discs soaked in each irrigation solution. The zones of inhibition were again recorded using the Digital Caliper mechanical micrometer.

\section{Calgary Biofilm Device}

A $10 \mathrm{uL}$ loop of organism sample from a blood agar plate was placed into $40 \mathrm{~mL}$ TSB.

The loop was swirled to ensure all the organism had been released from the loop into the solution. The solution was then vortexed to ensure an even mixture throughout. The organism containing solution was then delivered into a, 96-well, Innovotech Microtider tray (Figure 5), at a volume of $200 \mathrm{uL}$. The outer wells were excluded to reduce the risk of evaporation during the 
incubation period (Figure 6). Hydroxyapatite-coated pegs were then placed into the organism containing wells of the microtider tray. The microtider tray was incubated at 37 degrees Celsius for 48 hours. The tray was placed on a rocking table at a speed of 2.5 rocks per minute to ensure biofilm formation on each of the pegs.

Once the incubation time was complete, a microtider tray was prepared containing the irrigation solutions. The concentrations used were 100\% and 50\% Sodium Hypochlorite and $100 \%$ and $50 \%$ delmopinol hydrochloride. Saline was also used as the control. The biofilm coated pegs were placed into the solutions for 2 minutes to simulate irrigation time. The biofilm coated pegs were then placed in saline for 30 seconds to inhibit further effects of the irrigation solutions. After the saline irrigation, the pegs were broken off the tray with sterile needle nose pliers and were analyzed for percentage of biofilm coverage and scanning electron microscope images (Figure 7).

\section{Biofilm Coverage}

The pegs were broken from the Calgary Biofilm Device using sterile needle nose pliers and were stained with Crystal Violet for 30 seconds (Figure 8). The pegs were then analyzed in the Microscope Imaging Facility at West Virginia University using a Carl Zeiss Tissue Culture microscope. Biofilm coverage was determined using a crude assay of visual judgment. Images of the pegs were captured using the Carl Zeiss Imaging (CZI) software.

\section{Colony Forming Units}

The pegs were broken from the Calgary Biofilm Device and placed in test tubes with 4 milliliters of saline. The test tubes were sonicated at 37 degrees Celsius for 30 seconds. The sonication disrupts the biofilm, leaving it free floating within the solution. Three 1 in 10 
dilutions were then performed for each microorganism. $250 \mathrm{uL}$ were then placed on Mueller Hinton plates and dispersed with a L-spreader. The plates were then placed in an incubator at 37 degrees Celsius for 24 hours.

\section{Scanning Electron Microscope}

The pegs were broken from the Calgary Biofilm Device and placed into vials containing $10 \%$ neutral buffered formalin to preserve the biofilm formation. The targeted images focused on the "apical" one-third of the hydroxyapatite pegs. Images of the pegs were captured using a Hitachi S-4700 FE-SEM at a working distance of 12 millimeters, West Virginia University Department of Chemical Engineering, Jeremy Hardinger, following gold-palladium spulter to enhance conductivity allowing for visualization of architectural features. The images were captured at $200 \mu \mathrm{m}, 50 \mu \mathrm{m}, 20 \mu \mathrm{m}, 5 \mu \mathrm{m}$ and $2 \mu \mathrm{m}$ to better visualize topography, biofilm stage, and individual microorganisms. Pseudomonas aeruginosa and Staphylococcus aeurus were viewed beneath $2 \mu \mathrm{m}$ magnification due to the smaller size of the microorganisms.

\section{$\underline{\text { Data Collection }}$}

The Zones of Inhibition were measured using a digital caliper in millimeter increments. The measurements were then recorded in a laboratory notebook and converted to an Excel spreadsheet.

Biofilm coverage was analyzed by the principal investigator using a crude assay to determine coverage. The coverage was recorded in percentages and the results were compared for effectiveness of the solutions. 
Colony formation units were counted by dividing the Mueller Hinton plates into quadrants and multiplying the findings by four. The plates with too many colonies to accurately count were given the notation TNTC meaning "too numerous to count," and were given the number of 1000 for statistical purposes.

Scanning electron microscope images were analyzed to determine the amount of microorganisms present after a saline, sodium hypochlorite and delmopinol hydrochloride treatment. The images were organized in a quad analysis so that comparison could be made. The images are used to show the effectiveness of the irrigants and the presence of growth of the microorganisms.

\section{$\underline{\text { Statistics }}$}

Statistics were performed to determine if there was a significant difference between irrigating solutions. A One-Way ANOVA analysis and a Wilcoxon / Kruskal-Wallis Test were used to evaluate the data. 


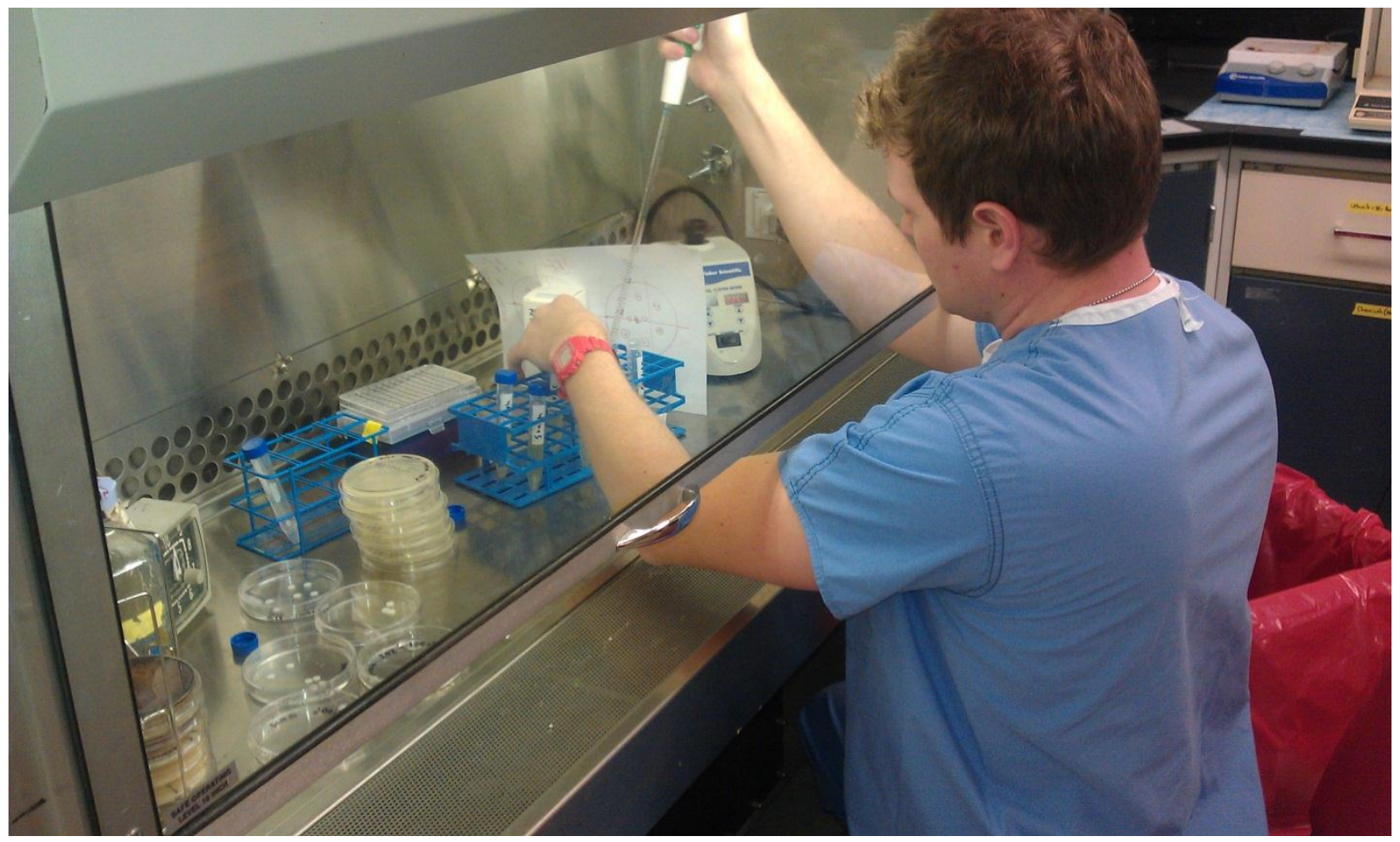

Figure 3 Principal investigator working on samples beneath the Class II Filtech biosafety hood. 


\section{Zones of Inhibition Treatment Diagram}

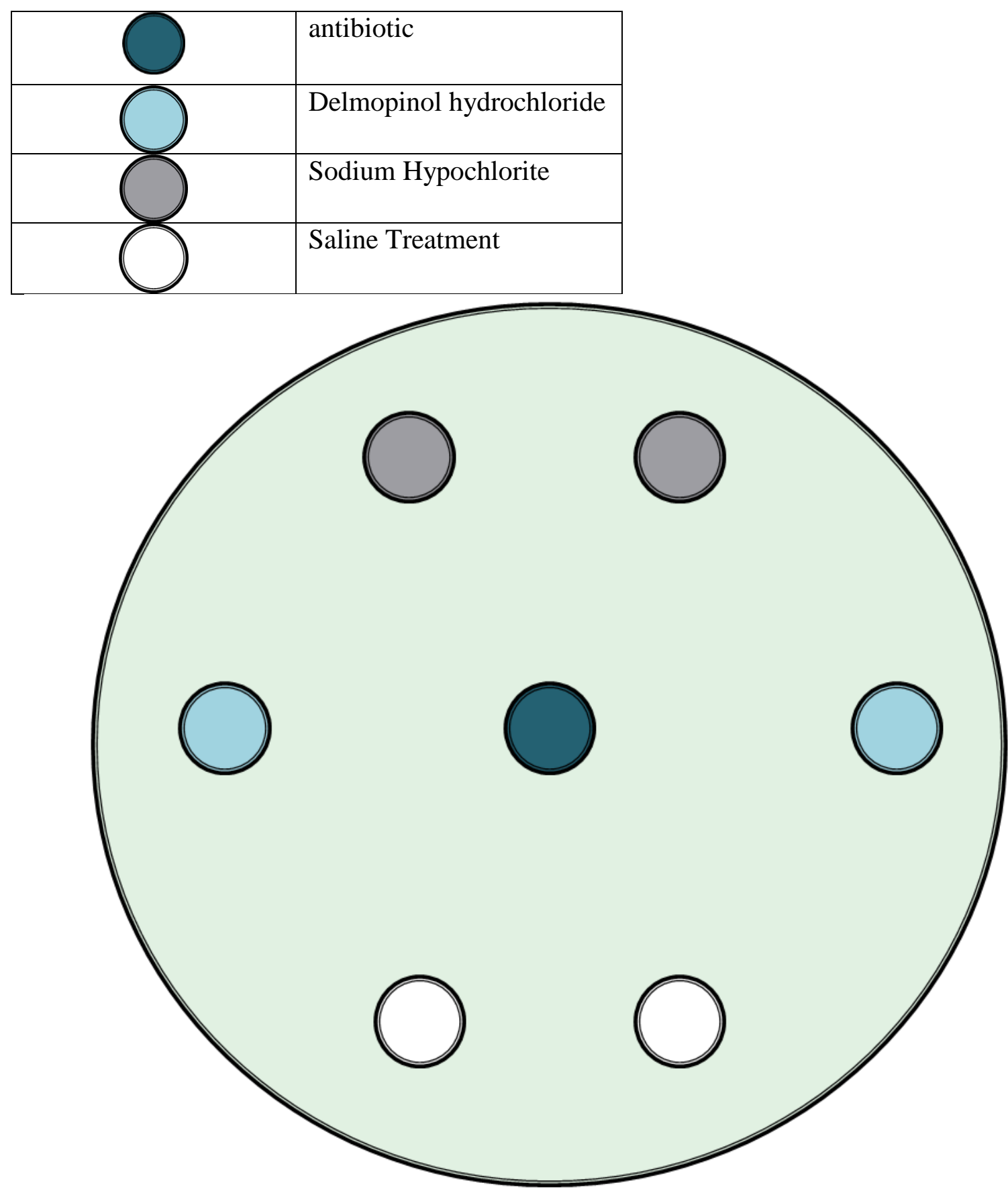

Figure 4 The discs were placed in this way to ensure no overlap of the zones of inhibition. 


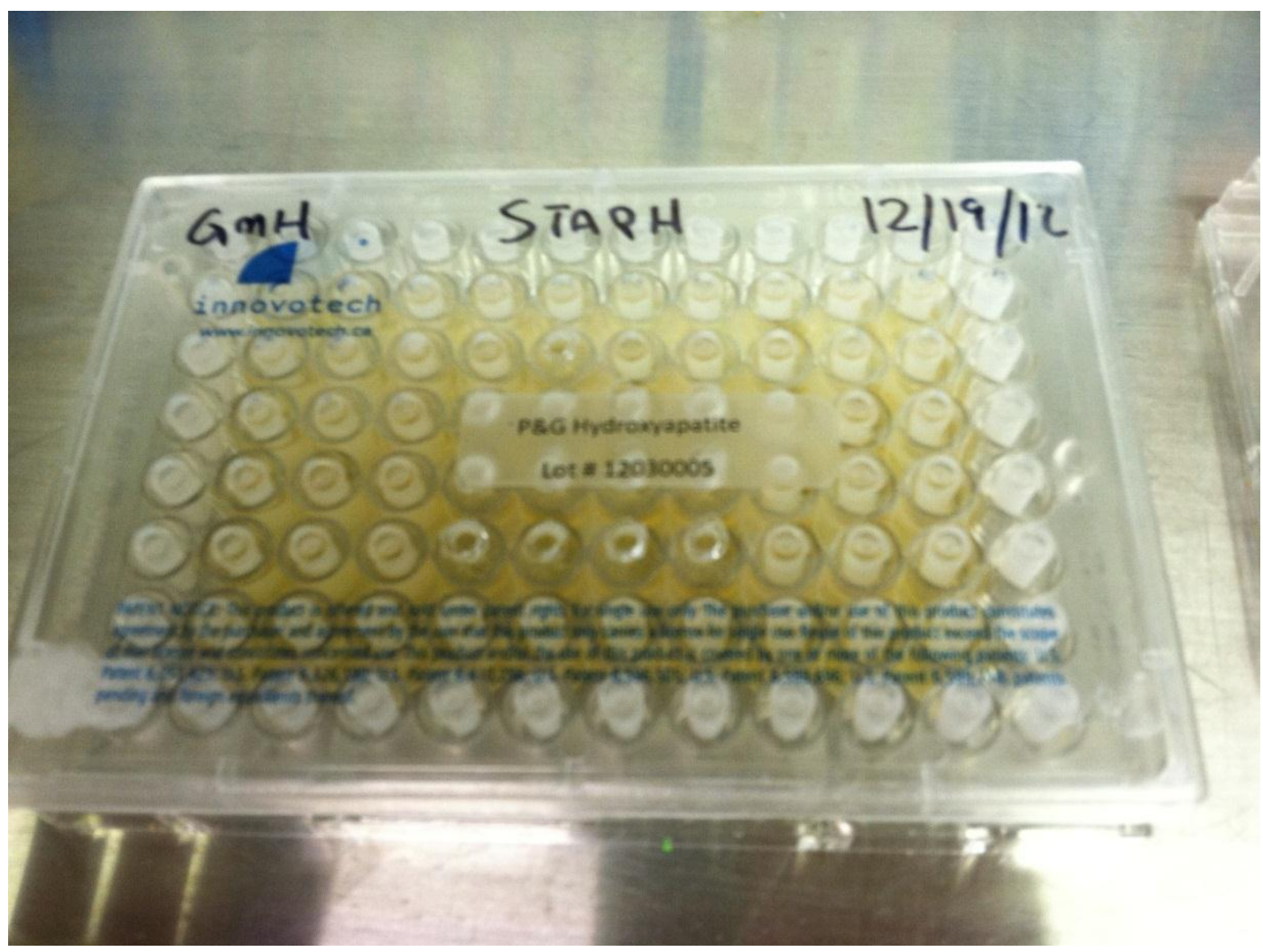

Figure 5 An example of the Calgary Biofilm Device used to simulate a tooth structure. 


\section{Calgary Biofilm Device Treatment Diagram}

\begin{tabular}{|l|l|}
\hline & $\begin{array}{l}\text { Sodium Hypochlorite } \\
\text { Treatment }\end{array}$ \\
\hline $\begin{array}{l}\text { Delmopinol Hydrochloride } \\
\text { Treatment }\end{array}$ \\
\hline Saline Treatment \\
\hline
\end{tabular}

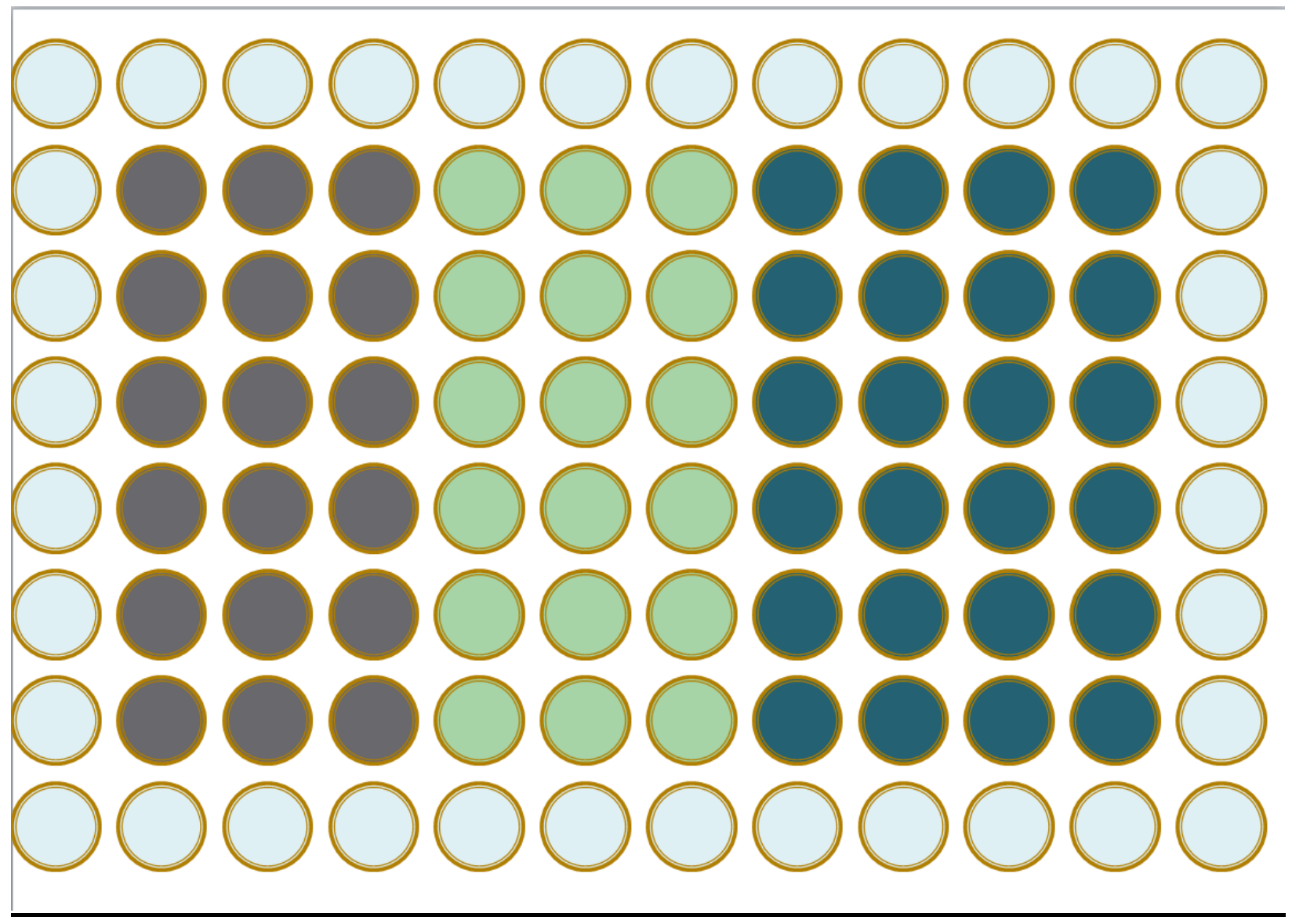

Figure 6 The wells used in the Calgary Biofilm Device for microorganisms separated by treatment. 


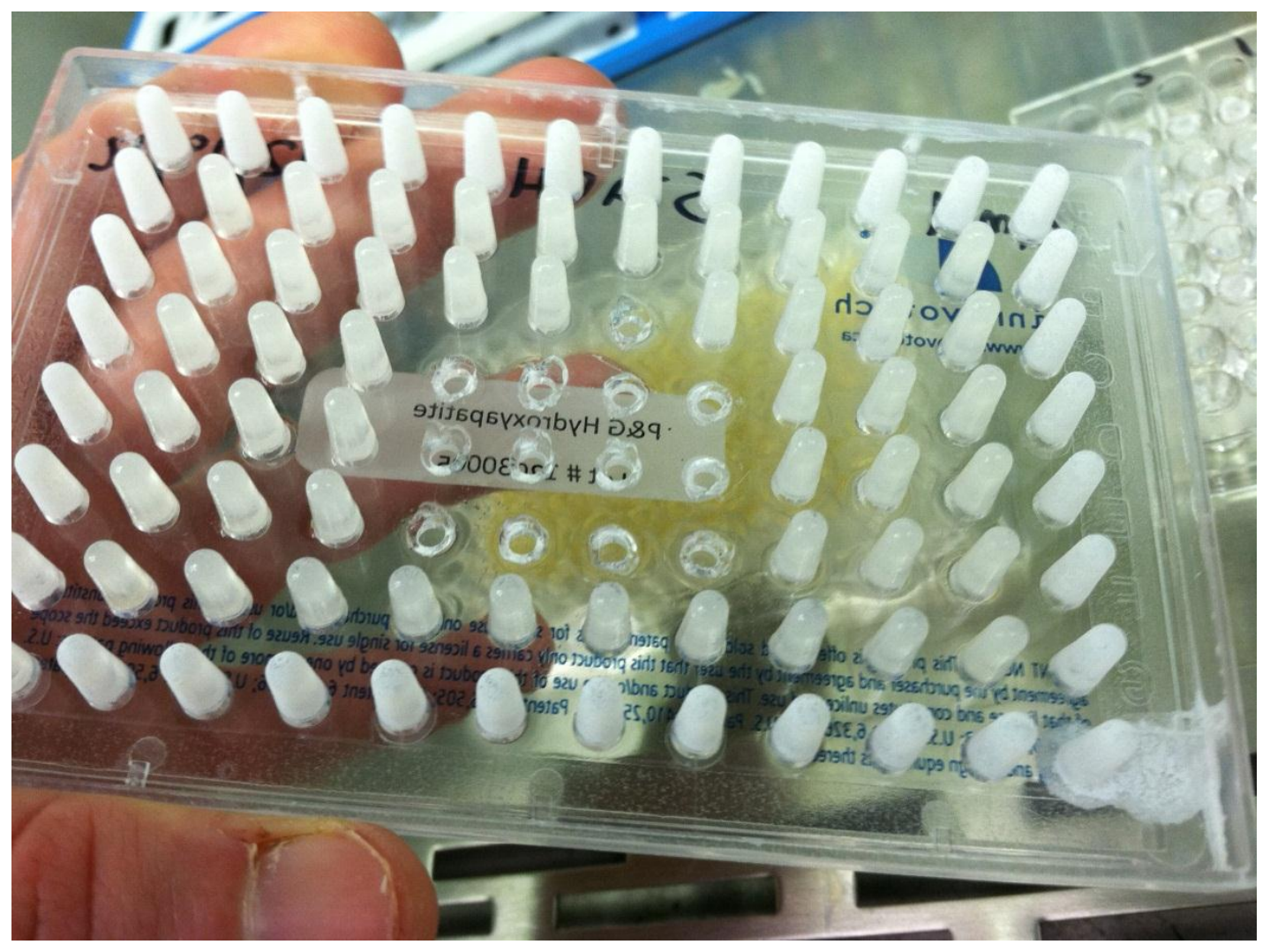

Figure 7 An example of the pegs removed for analysis from the Calgary Biofilm Device. 


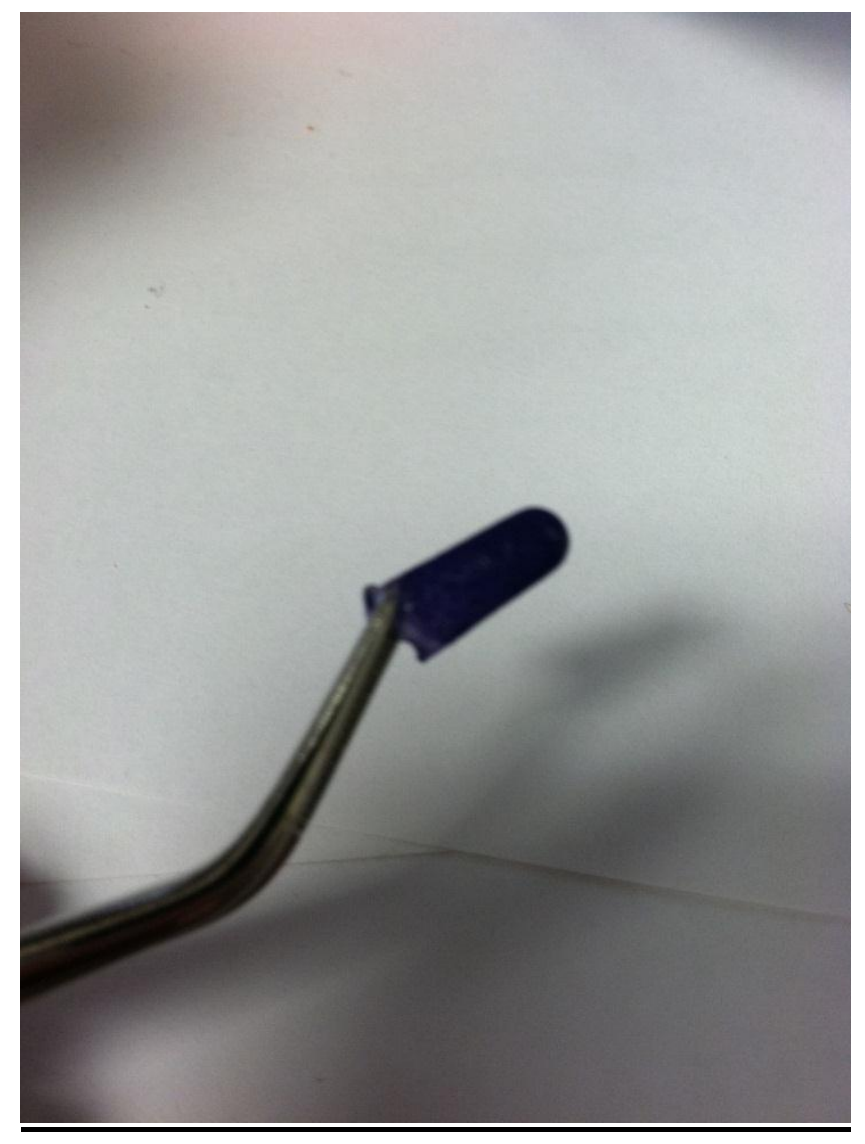

Figure 8 Biofilm Coverage, Crystal Violet Stained Peg 


\section{Chapter IV}

\section{$\underline{\text { Results }}$}

\section{$\underline{\text { Zones of Inhibition (ZOI) }}$}

The results of the analysis of the zones of inhibition were recorded in millimeters in a spreadsheet format. Averages and comparisons were performed between saline, $\mathrm{NaOCl}$ and $\mathrm{DH}$ for each microorganism. The results were also differentiated by the type of medium used, either Mueller Hinton or Poloxamer.

For each individual microorganism, $\mathrm{NaOCl}$ recorded the greatest diameter of inhibition zones, followed by DH and finally saline which resulted in minimal to no effect. These findings were present in both mediums tested. An average of each zone was recorded and charted for Poloxamer as seen in Table 1 and Figure 9. Also, an average of each xone was recorded and charted for Mueller Hinton as seen in Table 2 and Figure 10.

\section{Biofilm Coverage}

All Calgary Biofilm Device hydroxyapatite pegs were examined beneath a Carl Zeiss microscope and photographed at 5x magnification. The images were analyzed by the principal investigator and evaluated for biofilm coverage using a crude assay. The biofilm coverage was recorded on a percentage basis and recorded in a spreadsheet as seen in Figures 11, 12 and 13.

\section{Colony Forming Units}

A colony count was performed by dividing the plates into four quadrants and multiplying the colony count within each quadrant by four to determine a rough overall amount. This was 
not the case in plates that had few colonies present, allowing for accurate counting. The counts were recorded in a spreadsheet and are represented in Table 3, 4 and 5.

\section{Scanning Electron Microscope}

The images were analyzed based on the presence or absence of microorganisms only. The images were organized in an order of increased magnification $(200 \mu \mathrm{m}, 50 \mu \mathrm{m}, 20 \mu \mathrm{m}$ and 2 $\mu \mathrm{m}$ ) to show the presence of biofilm and microorganisms. (Figures 16, 17, 18, 19, 20, 21, 22, 23, 24, 25 and 26) Magnification indicated in template presented in a quad analysis.

\section{$\underline{\text { Statistics }}$}

The results of the Oneway ANOVA analysis of the Zones of Inhibition revealed a p-value of .0028. This indicates that sodium hypochlorite was statistically more significant compared to delmopinol hydrochloride in the reduction of both planktonic and biofilm forms of the prokaryote and eukaryote microorganisms as tested. 


\begin{tabular}{|c|c|c|c|c|}
\hline Poloxamer & Third Study & Zones of & Inhibition & $\begin{array}{c}25 \% \\
\text { Solution }\end{array}$ \\
\hline SOLUTION & Plate \# & S. aeurus & P. aeruginosa & C. albicans \\
\hline \multirow{2}{*}{$\mathrm{NaOCl}$} & Ia & $19.01 \mathrm{~mm}$ & $27.60 \mathrm{~mm}$ & $35.16 \mathrm{~mm}$ \\
\hline & $\mathrm{Ib}$ & $17.55 \mathrm{~mm}$ & $26.20 \mathrm{~mm}$ & $36.82 \mathrm{~mm}$ \\
\hline \multirow[t]{2}{*}{ DH } & Ia & $8.22 \mathrm{~mm}$ & $9.47 \mathrm{~mm}$ & $7.86 \mathrm{~mm}$ \\
\hline & $\mathrm{Ib}$ & $8.16 \mathrm{~mm}$ & $9.02 \mathrm{~mm}$ & $7.92 \mathrm{~mm}$ \\
\hline \multirow[t]{2}{*}{ Saline } & Ia & $0 \mathrm{~mm}$ & $0 \mathrm{~mm}$ & $0 \mathrm{~mm}$ \\
\hline & $\mathrm{Ib}$ & $0 \mathrm{~mm}$ & $0 \mathrm{~mm}$ & $0 \mathrm{~mm}$ \\
\hline \multirow[t]{2}{*}{$\mathrm{NaOCl}$} & IIa & $19.33 \mathrm{~mm}$ & $25.56 \mathrm{~mm}$ & $37.38 \mathrm{~mm}$ \\
\hline & $\mathrm{IIb}$ & $15.71 \mathrm{~mm}$ & $27.38 \mathrm{~mm}$ & $36.02 \mathrm{~mm}$ \\
\hline \multirow[t]{2}{*}{ DH } & IIa & $7.75 \mathrm{~mm}$ & $9.68 \mathrm{~mm}$ & $8.42 \mathrm{~mm}$ \\
\hline & $\mathrm{IIb}$ & $8.02 \mathrm{~mm}$ & $8.88 \mathrm{~mm}$ & $8.16 \mathrm{~mm}$ \\
\hline \multirow[t]{2}{*}{ Saline } & IIa & $0 \mathrm{~mm}$ & $0 \mathrm{~mm}$ & $0 \mathrm{~mm}$ \\
\hline & $\mathrm{IIb}$ & $0 \mathrm{~mm}$ & $0 \mathrm{~mm}$ & $0 \mathrm{~mm}$ \\
\hline \multirow[t]{2}{*}{$\mathrm{NaOCl}$} & IIIa & $16.98 \mathrm{~mm}$ & $29.18 \mathrm{~mm}$ & $34.12 \mathrm{~mm}$ \\
\hline & IIIb & $13.96 \mathrm{~mm}$ & $28.76 \mathrm{~mm}$ & $35.62 \mathrm{~mm}$ \\
\hline \multirow[t]{2}{*}{ DH } & IIIa & $8.42 \mathrm{~mm}$ & $9.82 \mathrm{~mm}$ & $9.32 \mathrm{~mm}$ \\
\hline & IIIb & $7.96 \mathrm{~mm}$ & $9.00 \mathrm{~mm}$ & $8.74 \mathrm{~mm}$ \\
\hline \multirow[t]{2}{*}{ Saline } & IIIa & $0 \mathrm{~mm}$ & $0 \mathrm{~mm}$ & $0 \mathrm{~mm}$ \\
\hline & IIIb & $0 \mathrm{~mm}$ & $0 \mathrm{~mm}$ & $0 \mathrm{~mm}$ \\
\hline
\end{tabular}

Table 1: Chart showing the average zones of inhibition of each solution's effect on the studied microorganisms. 


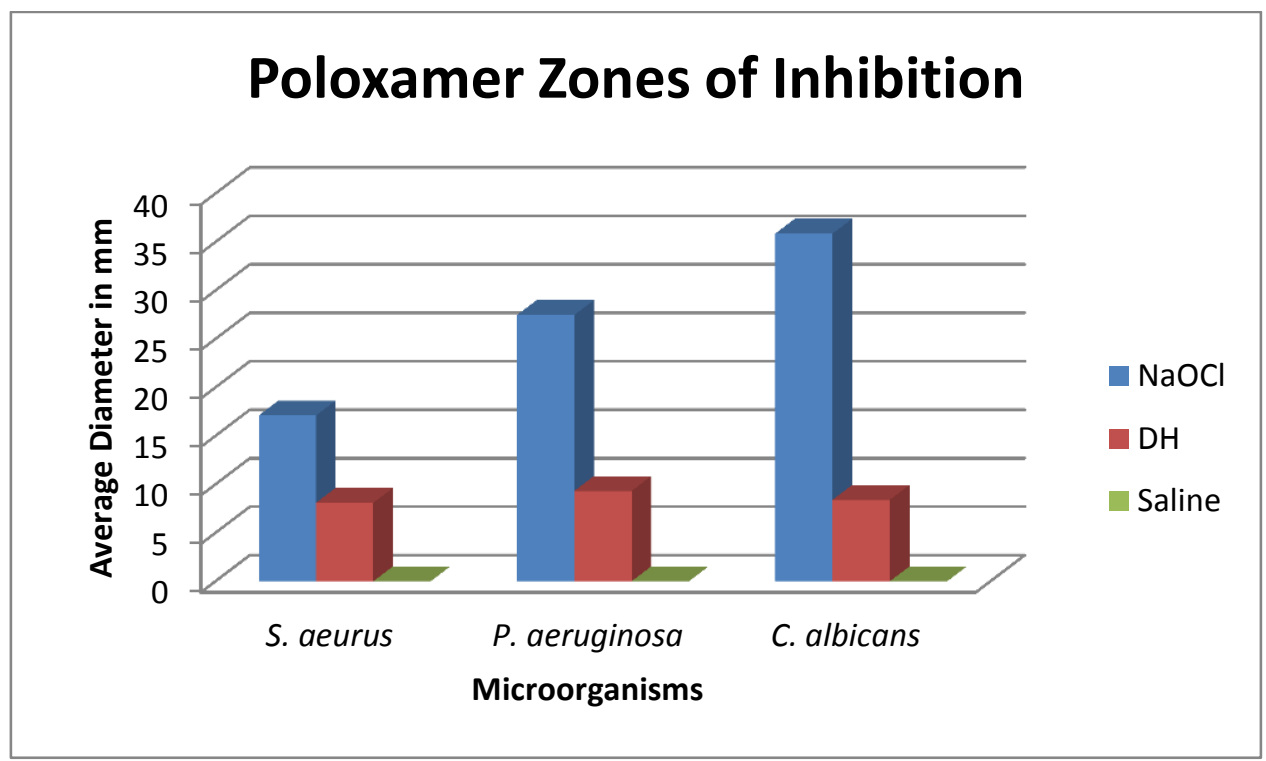

Figure 9 Bar graph representing the comparison of each solution's effect on the prokaryotes and eukaryote. 


\begin{tabular}{|c|c|c|c|c|}
\hline $\begin{array}{c}\text { Mueller } \\
\text { Hinton }\end{array}$ & $\begin{array}{l}\text { Third } \\
\text { Study }\end{array}$ & Zones of & Inhibition & $\begin{array}{c}25 \% \\
\text { Solution }\end{array}$ \\
\hline SOLUTION & Plate \# & S. aeurus & P. aeruginosa & C. albicans \\
\hline \multirow[t]{2}{*}{$\mathrm{NaOCl}$} & Ia & $18.34 \mathrm{~mm}$ & $13.24 \mathrm{~mm}$ & $33.18 \mathrm{~mm}$ \\
\hline & $\mathrm{Ib}$ & $16.95 \mathrm{~mm}$ & $11.84 \mathrm{~mm}$ & $32.44 \mathrm{~mm}$ \\
\hline \multirow[t]{2}{*}{ DH } & Ia & $0 \mathrm{~mm}$ & $0 \mathrm{~mm}$ & $0 \mathrm{~mm}$ \\
\hline & $\mathrm{Ib}$ & $0 \mathrm{~mm}$ & $0 \mathrm{~mm}$ & $0 \mathrm{~mm}$ \\
\hline \multirow[t]{2}{*}{ Saline } & Ia & $0 \mathrm{~mm}$ & $0 \mathrm{~mm}$ & $0 \mathrm{~mm}$ \\
\hline & $\mathrm{Ib}$ & $0 \mathrm{~mm}$ & $0 \mathrm{~mm}$ & $0 \mathrm{~mm}$ \\
\hline \multirow[t]{2}{*}{$\mathrm{NaOCl}$} & IIa & $19.74 \mathrm{~mm}$ & $12.34 \mathrm{~mm}$ & $34.75 \mathrm{~mm}$ \\
\hline & $\mathrm{IIb}$ & $17.74 \mathrm{~mm}$ & $11.68 \mathrm{~mm}$ & $35.81 \mathrm{~mm}$ \\
\hline \multirow[t]{2}{*}{ DH } & IIa & $0 \mathrm{~mm}$ & $0 \mathrm{~mm}$ & $0 \mathrm{~mm}$ \\
\hline & $\mathrm{IIb}$ & $0 \mathrm{~mm}$ & $0 \mathrm{~mm}$ & $0 \mathrm{~mm}$ \\
\hline \multirow[t]{2}{*}{ Saline } & IIa & $0 \mathrm{~mm}$ & $0 \mathrm{~mm}$ & $0 \mathrm{~mm}$ \\
\hline & $\mathrm{IIb}$ & $0 \mathrm{~mm}$ & $0 \mathrm{~mm}$ & $0 \mathrm{~mm}$ \\
\hline \multirow[t]{2}{*}{$\mathrm{NaOCl}$} & IIIa & $20.98 \mathrm{~mm}$ & $11.02 \mathrm{~mm}$ & $34.28 \mathrm{~mm}$ \\
\hline & IIIb & $17.28 \mathrm{~mm}$ & $10.58 \mathrm{~mm}$ & $36.17 \mathrm{~mm}$ \\
\hline \multirow[t]{2}{*}{ DH } & IIIa & $0 \mathrm{~mm}$ & $0 \mathrm{~mm}$ & $0 \mathrm{~mm}$ \\
\hline & IIIb & $0 \mathrm{~mm}$ & $0 \mathrm{~mm}$ & $0 \mathrm{~mm}$ \\
\hline \multirow[t]{2}{*}{ Saline } & IIIa & $0 \mathrm{~mm}$ & $0 \mathrm{~mm}$ & $0 \mathrm{~mm}$ \\
\hline & IIIb & $0 \mathrm{~mm}$ & $0 \mathrm{~mm}$ & $0 \mathrm{~mm}$ \\
\hline
\end{tabular}

Table 2: Chart showing the average zones of inhibition of each solution's effect on the studied microorganisms. 


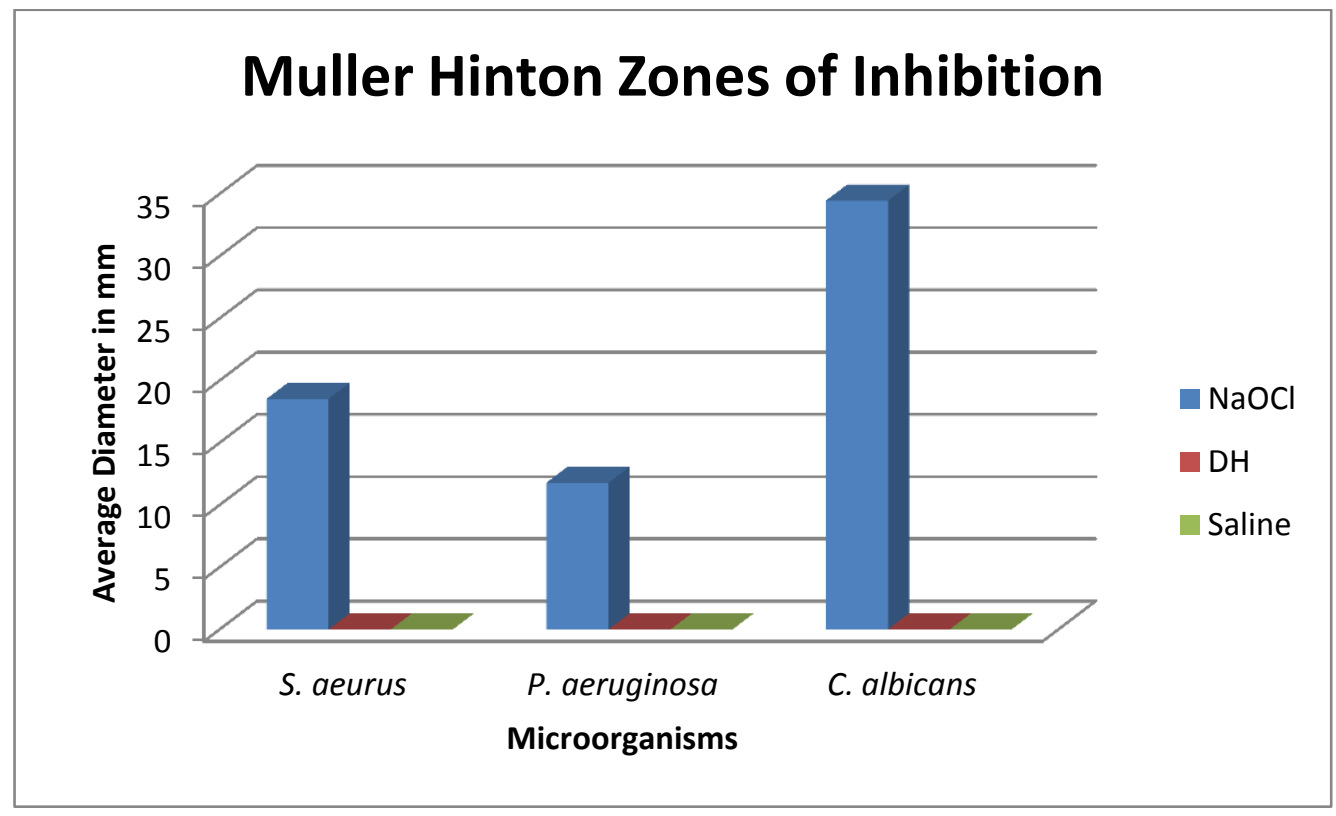

Figure 10 Bar graph representing the comparison of each solution's effect on the prokaryotes and eukaryote. 
Staphylococcus aeurus - Biofilm Coverage using Calgary Biofilm Device (Pegs)

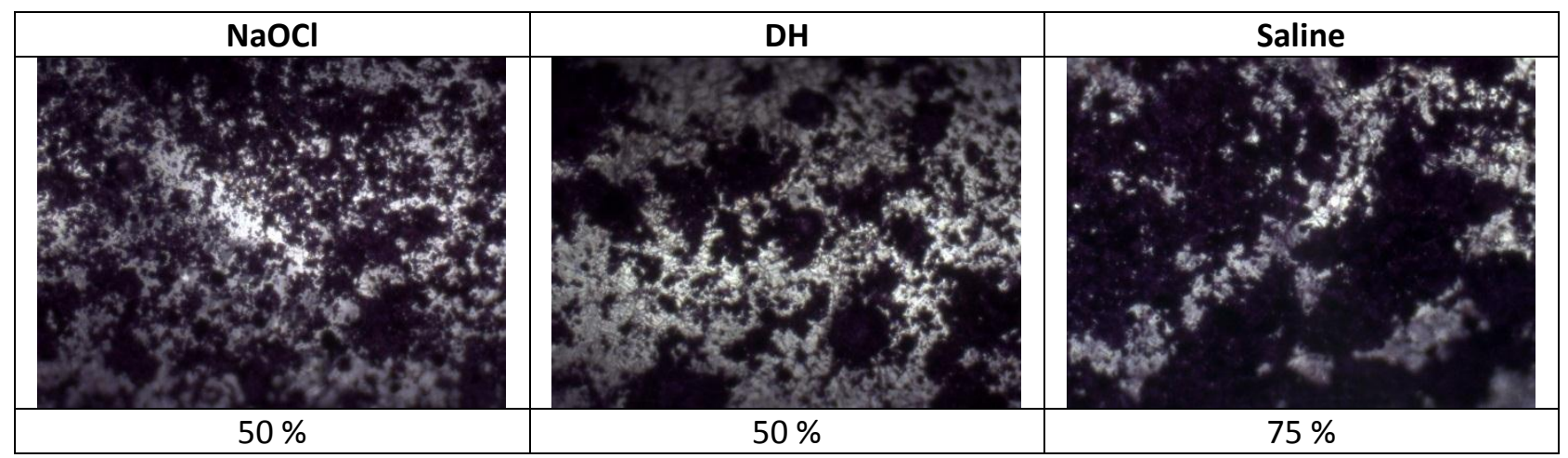

Figure 11 Pegs stained in Crystal Violet to determine biofilm coverage recorded in percentages.

\section{Pseudomonas aeruginosa - Biofilm Coverage using Calgary Biofilm Device (Pegs)}

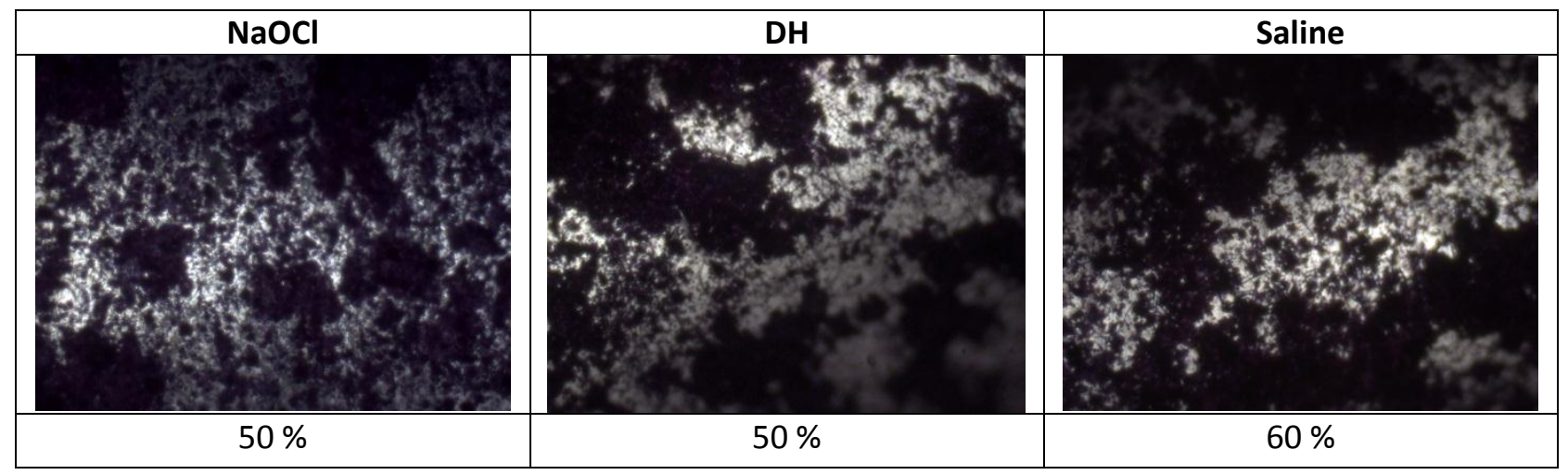

Figure 12 Pegs stained in Crystal Violet to determine biofilm coverage recorded in percentages.

Candida albicans - Biofilm Coverage using Calgary Biofilm Device (Pegs)

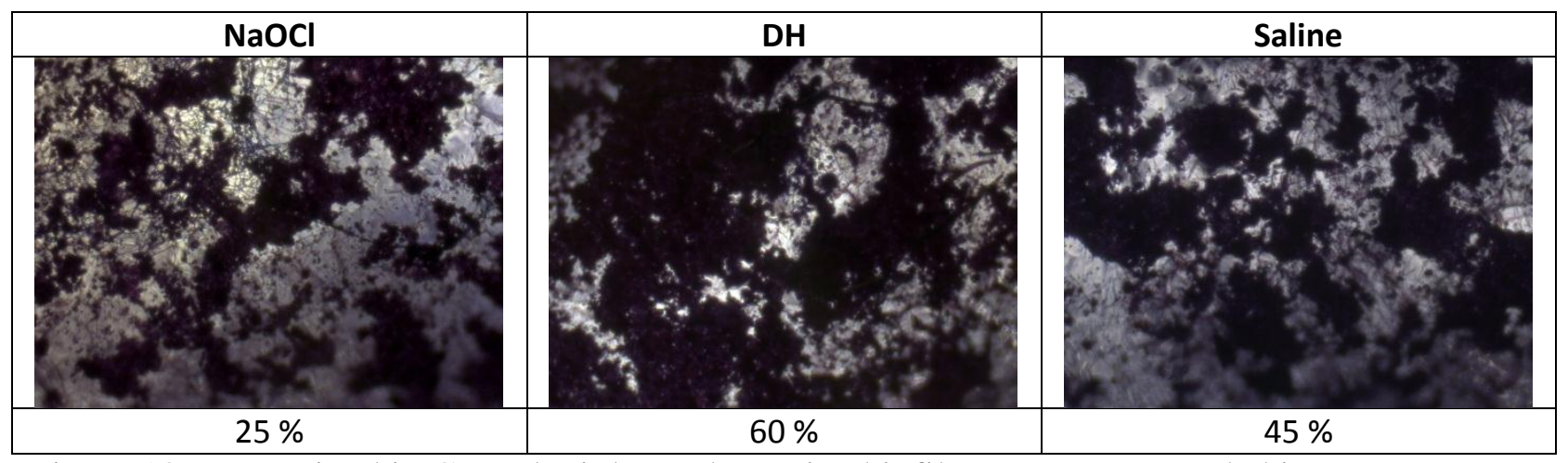

Figure 13 Pegs stained in Crystal Violet to determine biofilm coverage recorded in percentages. 


\begin{tabular}{|l|c|c|c|}
\hline Organism & Solution & Dilution & Count \\
\hline S. aeurus & $\mathrm{NaOCl}$ & -2 & 0 \\
\hline S. aeurus & $\mathrm{NaOCl}$ & -4 & 0 \\
\hline S. aeurus & $\mathrm{NaOCl}$ & -6 & 0 \\
\hline S. aeurus & $\mathrm{DH}$ & -2 & 4 \\
\hline S. aeurus & $\mathrm{DH}$ & -4 & 0 \\
\hline S. aeurus & $\mathrm{DH}$ & -6 & 0 \\
\hline S. aeurus & Saline & -2 & 1000 \\
\hline S. aeurus & Saline & -4 & 280 \\
\hline S. aeurus & Saline & -6 & 8 \\
\hline
\end{tabular}

Table 3: Colony count per organism after treatment with solutions.

\begin{tabular}{|c|c|c|c|}
\hline Organism & Solution & Dilution & Count \\
\hline P. aeruginosa & $\mathrm{NaOCl}$ & -2 & 0 \\
\hline P. aeruginosa & $\mathrm{NaOCl}$ & -4 & 0 \\
\hline P. aeruginosa & $\mathrm{NaOCl}$ & -6 & 0 \\
\hline P. aeruginosa & $\mathrm{DH}$ & -2 & 30 \\
\hline P. aeruginosa & DH & -4 & 6 \\
\hline P. aeruginosa & DH & -6 & 0 \\
\hline P. aeruginosa & Saline & -2 & 1000 \\
\hline P. aeruginosa & Saline & -4 & 1000 \\
\hline P. aeruginosa & Saline & -6 & 1000 \\
\hline
\end{tabular}

Table 4: Colony count per organism after treatment with solutions.

\begin{tabular}{|l|c|c|c|}
\hline Organism & Solution & Dilution & Count \\
\hline C. albicans & $\mathrm{NaOCl}$ & -2 & 0 \\
\hline C. albicans & $\mathrm{NaOCl}$ & -4 & 0 \\
\hline C. albicans & $\mathrm{NaOCl}$ & -6 & 0 \\
\hline C. albicans & $\mathrm{DH}$ & -2 & 26 \\
\hline C. albicans & $\mathrm{DH}$ & -4 & 0 \\
\hline C. albicans & $\mathrm{DH}$ & -6 & 0 \\
\hline C. albicans & Saline & -2 & 1000 \\
\hline C. albicans & Saline & -4 & 160 \\
\hline C. albicans & Saline & -6 & 14 \\
\hline
\end{tabular}

Table 5: Colony count per organism after treatment with solutions. 


\section{Scanning Electron Microscope Image Analysis Template of Biofilm on Hydroxyapatite Pegs}

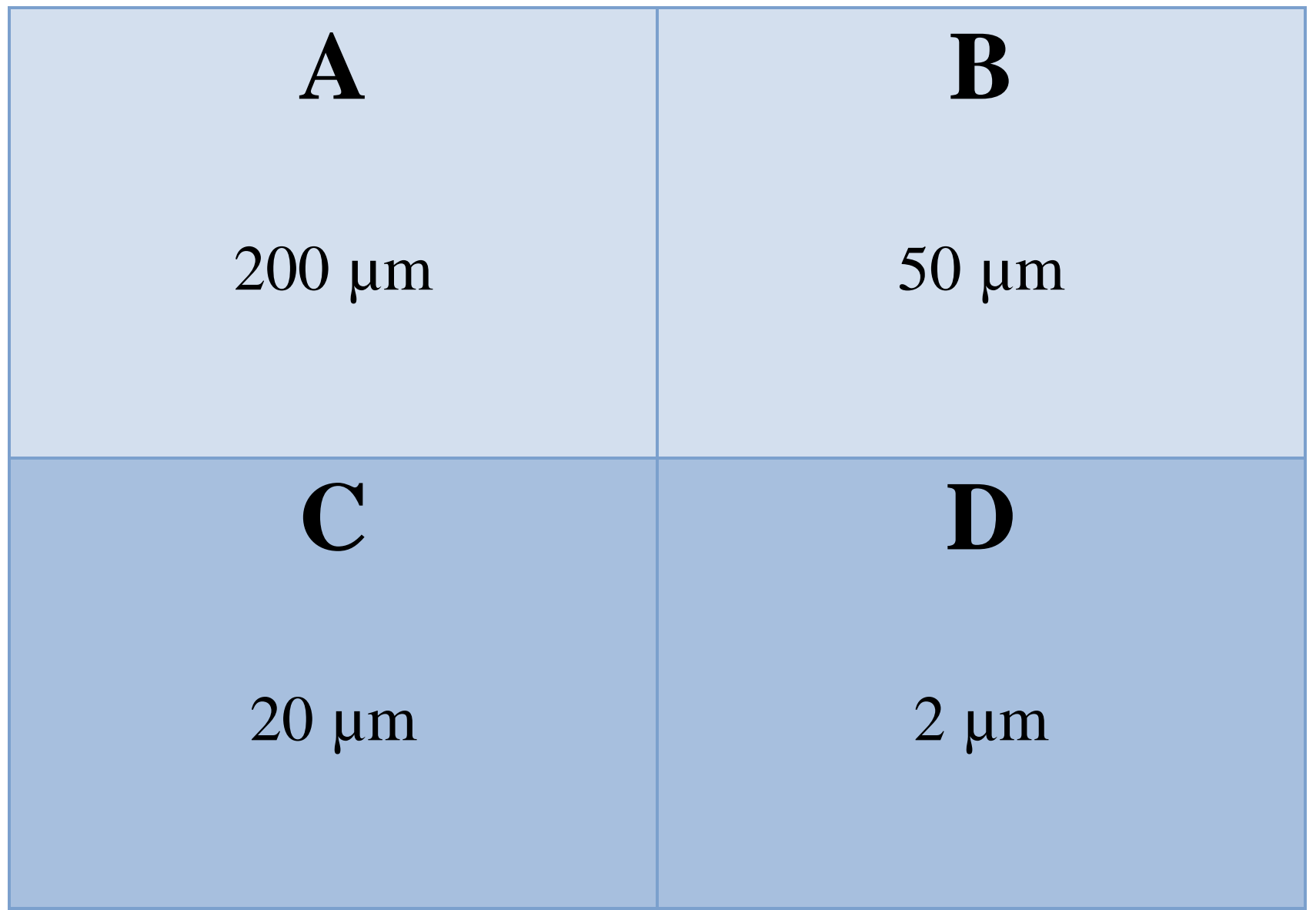

Figure $14200 \mu \mathrm{m}$ (A) establishes overall integrity and topography of large surface area, 50 (B) and $20 \mu \mathrm{m}$ (C) highlight the three-dimensional architecture of the Biofilm. $2 \mu \mathrm{m}$ (D) shows the microbial composition and organization of the Biofilm stage (I-IV) relative to multiple structural features and characteristics. "O" denotes areas of interest and highlight specific features key in study analysis described. 
Increase in Magnification Necessary for the Analysis of Biofilm Phenotype Formation on Apical One-third of Hydroxyapatite Pegs

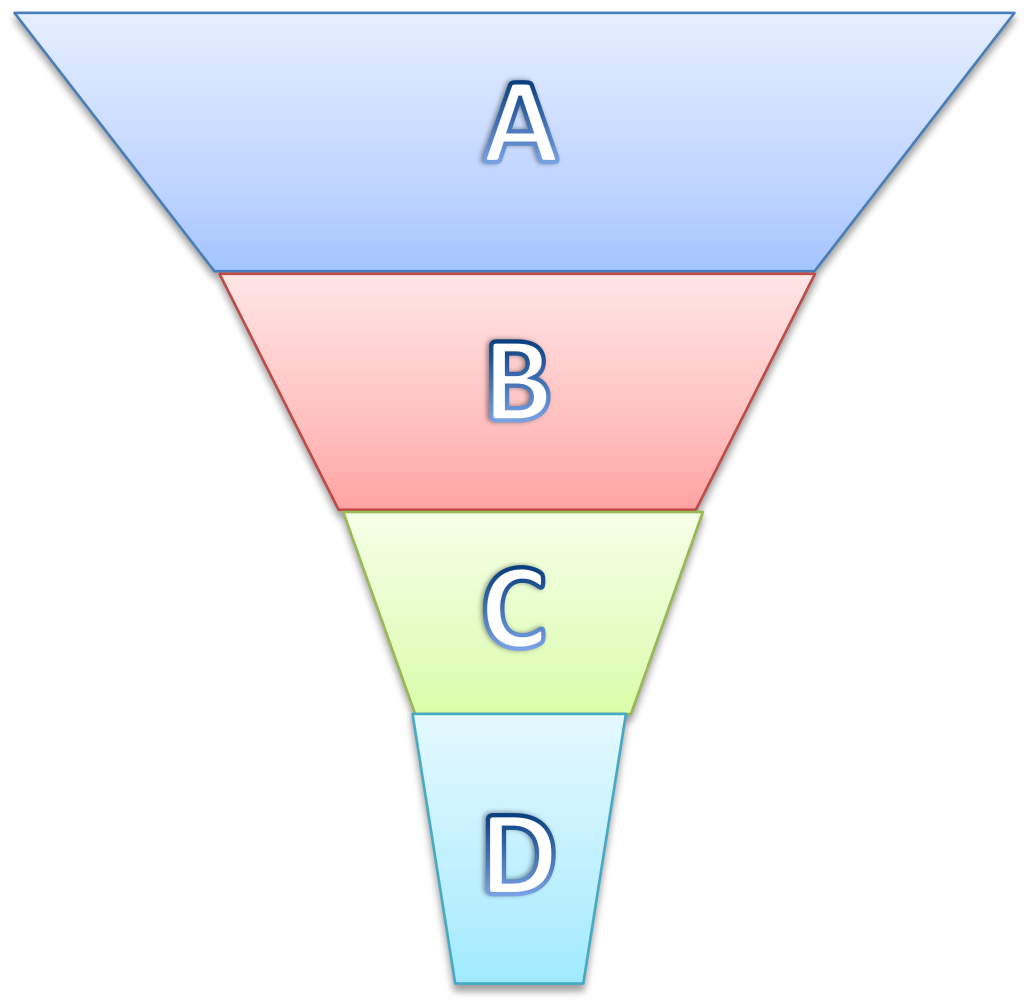

Figure $15200 \boldsymbol{\mu m}$ (A) shows overall surface integrity and topography. B (50 $\boldsymbol{\mu m}$ ) demonstrates biofilm three-dimensional architecture. $\mathrm{C}(\mathbf{2 0} \boldsymbol{\mu m})$ give microbial composition and biofilm stages (I-IV). D $(\mathbf{2} \boldsymbol{\mu m})$ shows individual microorganisms. 


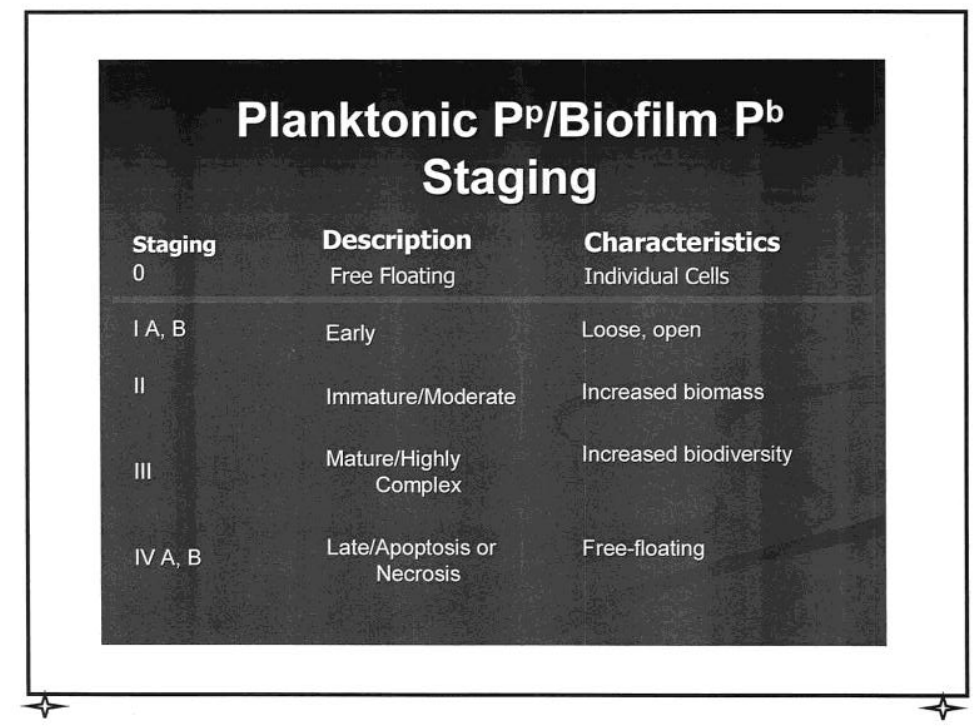

Figure 16 Biofilms (Stages II and III) are considered "resilient" to anti-infectives based on the "Super Genome" and multiple gradients (structural and physiologic) within the community. A structural biofilm (Stage III) representation is shown in Figure 16. Courtesy of Dr. John G Thomas

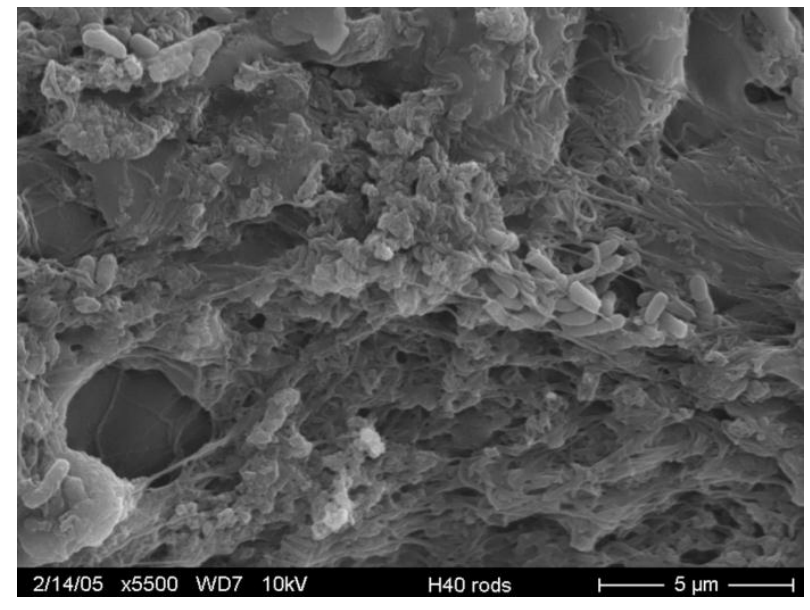

Figure 17 A structural biofilm example (Stage III) to demonstrate three-dimensional sturucture. Courtesy of Dr. John G. Thomas 


\section{Staphylococcus aeurus Biofilm Phenotype - NaOCl Treatment}

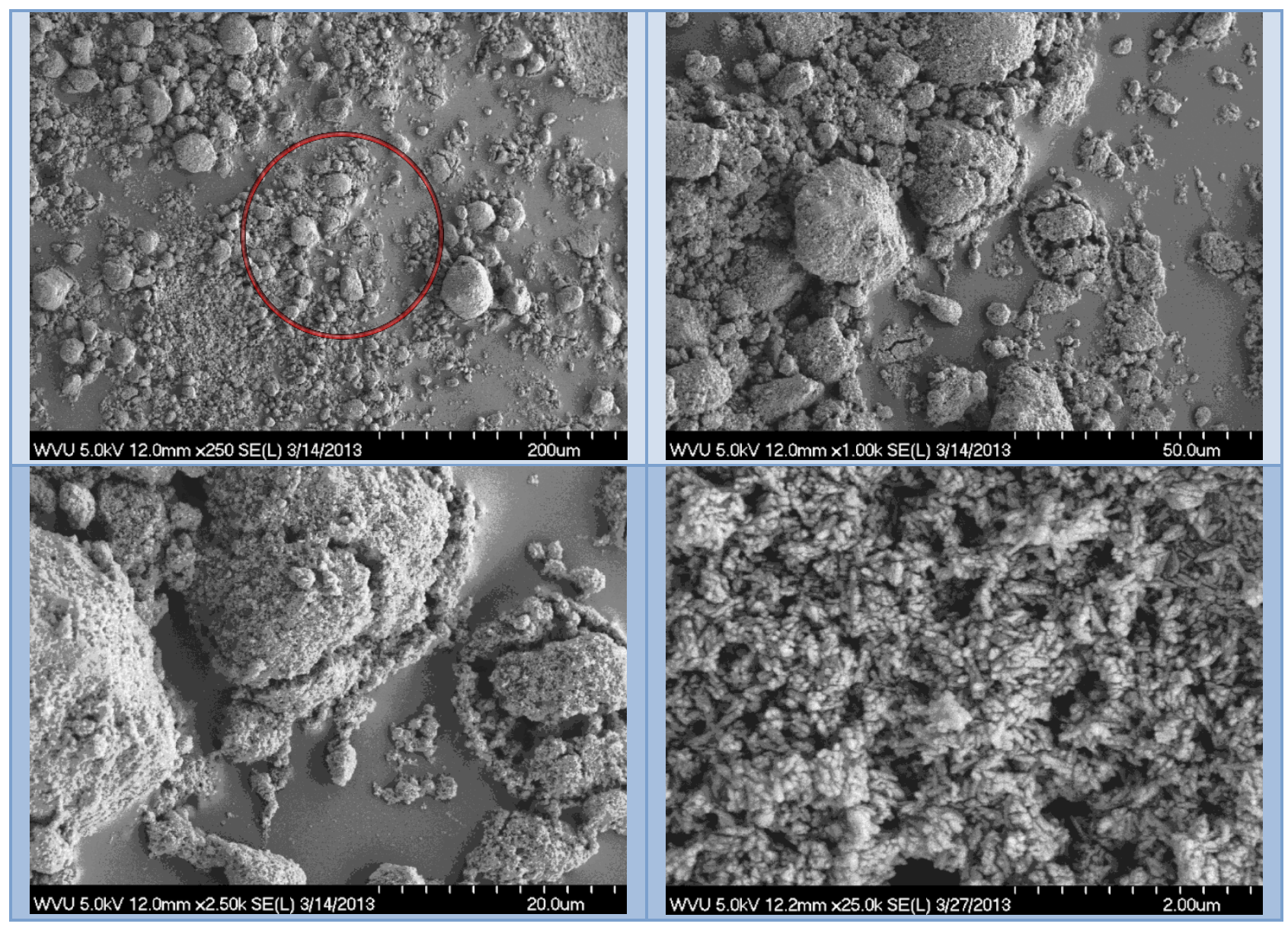

Figure 18 Well established Gram-positive Biofilm (BF) stages, III and IV, with universal surface coverage. Minimal impact of treatment. (O) 


\section{Staphylococcus aeurus Biofilm Phenotype - DH Treatment}

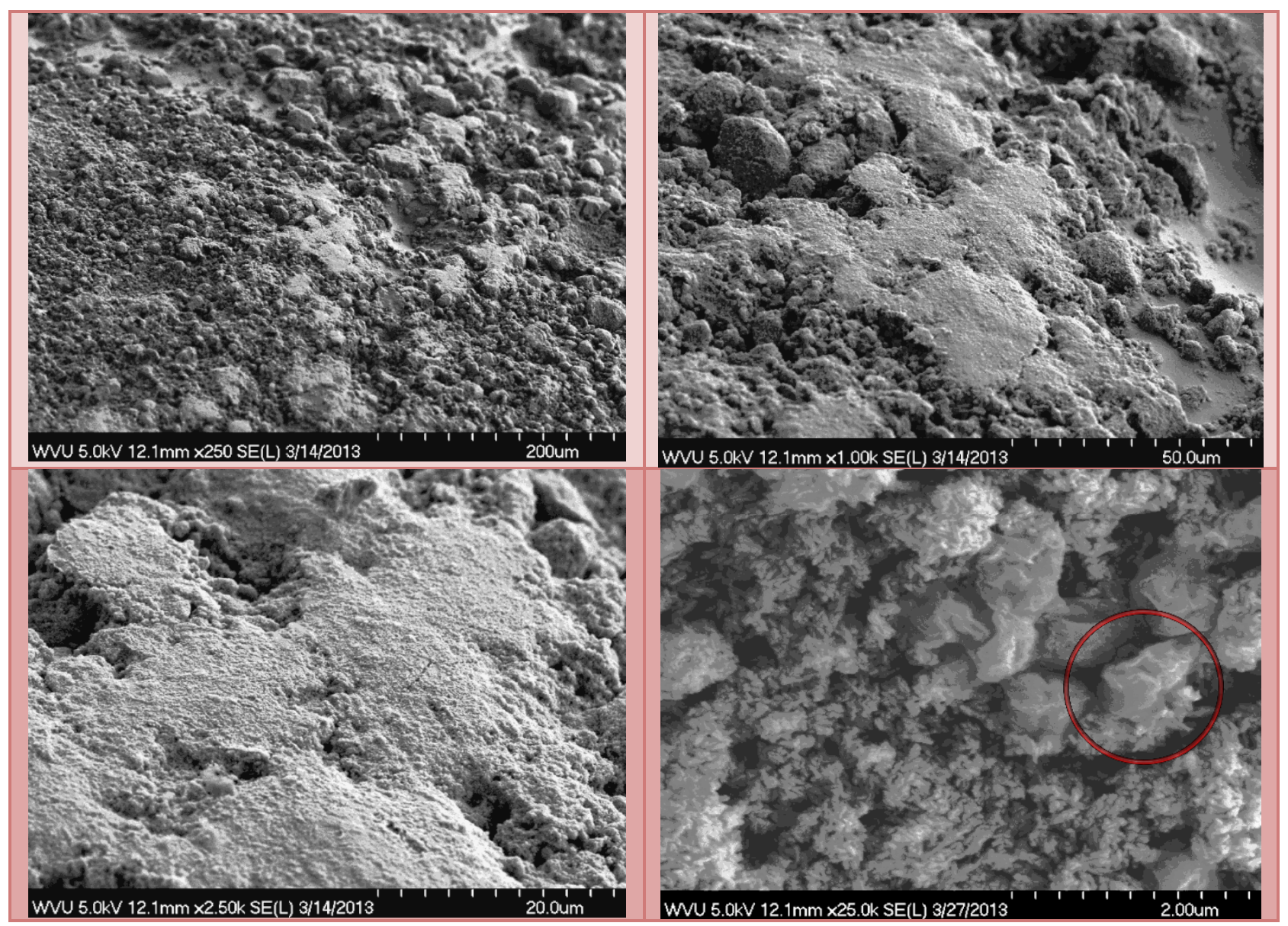

Figure 19 Altered topography with reduced column formation, but well defined BF, stages III and IV. Some intervention as a result of treatment. (O) 


\section{Staphylococcus aeurus Biofilm Phenotype - Saline Treatment}

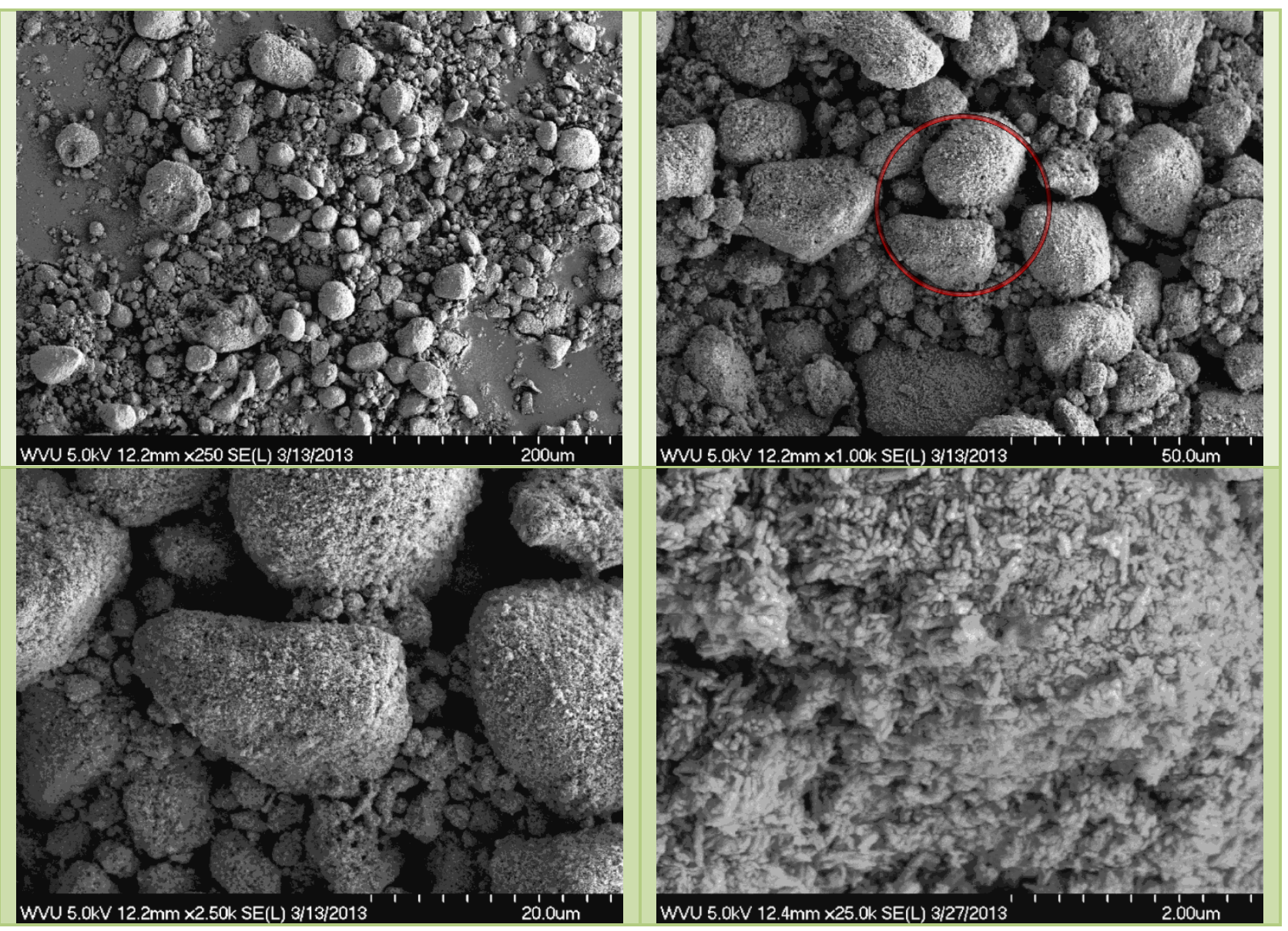

Figure 20 Well established, mature, Gram-positive BF, stage III, with traditional "pods" and "columns," area of interest. (O) 


\section{Pseudomonas aeruginosa Biofilm Phenotype - NaOCl Treatment}

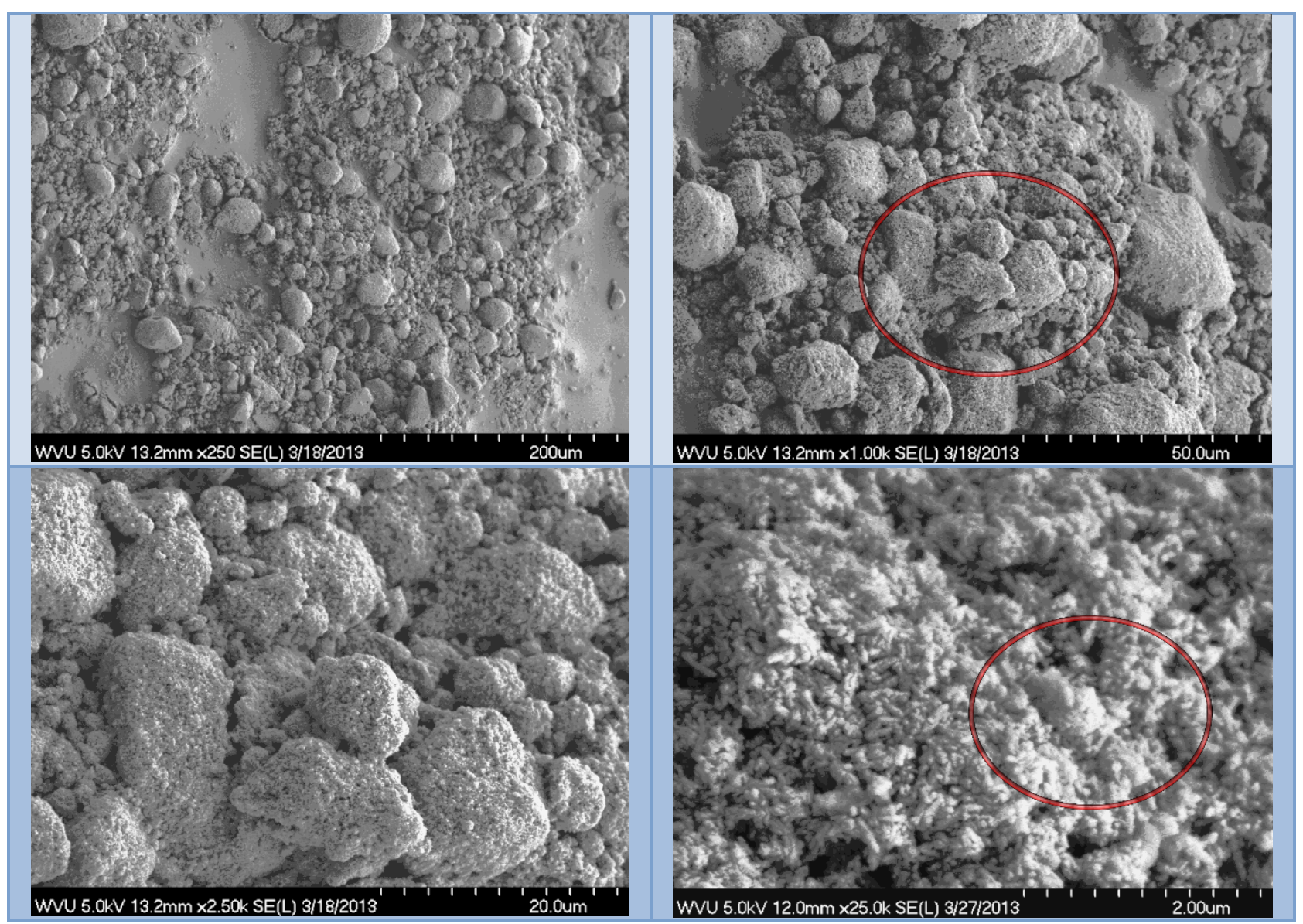

Figure 21 Stage IV BF evenly distributed with multiple "silos", "columns" and "pods." Some reduction in typical Gram-negative architecture at $2.0 \mu \mathrm{m}$. (O) 


\section{Pseudomonas aeruginosa Biofilm Phenotype - DH Treatment}

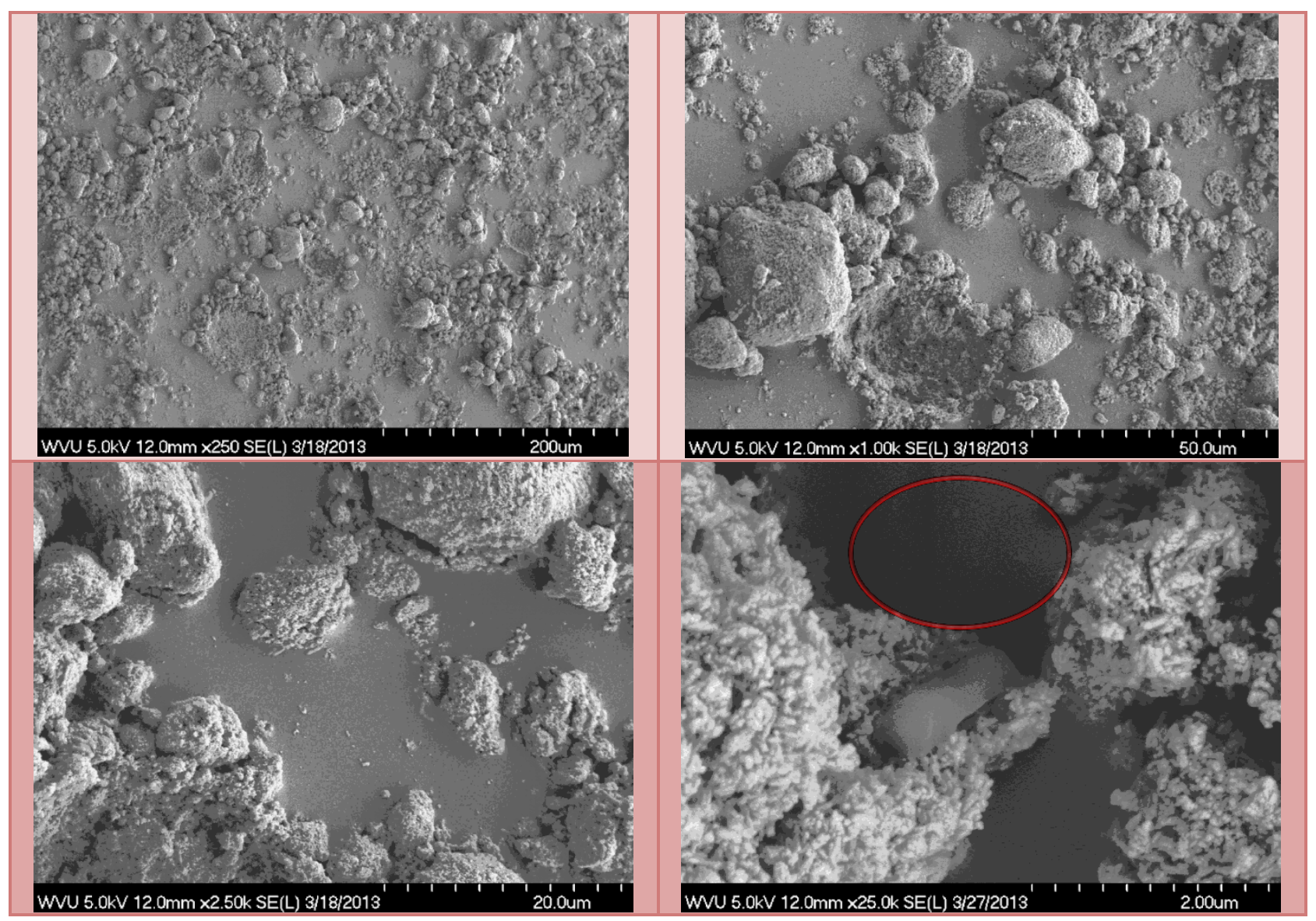

Figure 22 Significant alteration in topography of Gram-negative BF, stage IV. Marked reduction in surface area coverage $(\sim 50 \%)$ at $20 \mu \mathrm{m}$ and reduced pods seen at $2 \mu \mathrm{m}$. (O) 


\section{Pseudomonas aeruginosa Biofilm Phenotype - Saline Treatment}

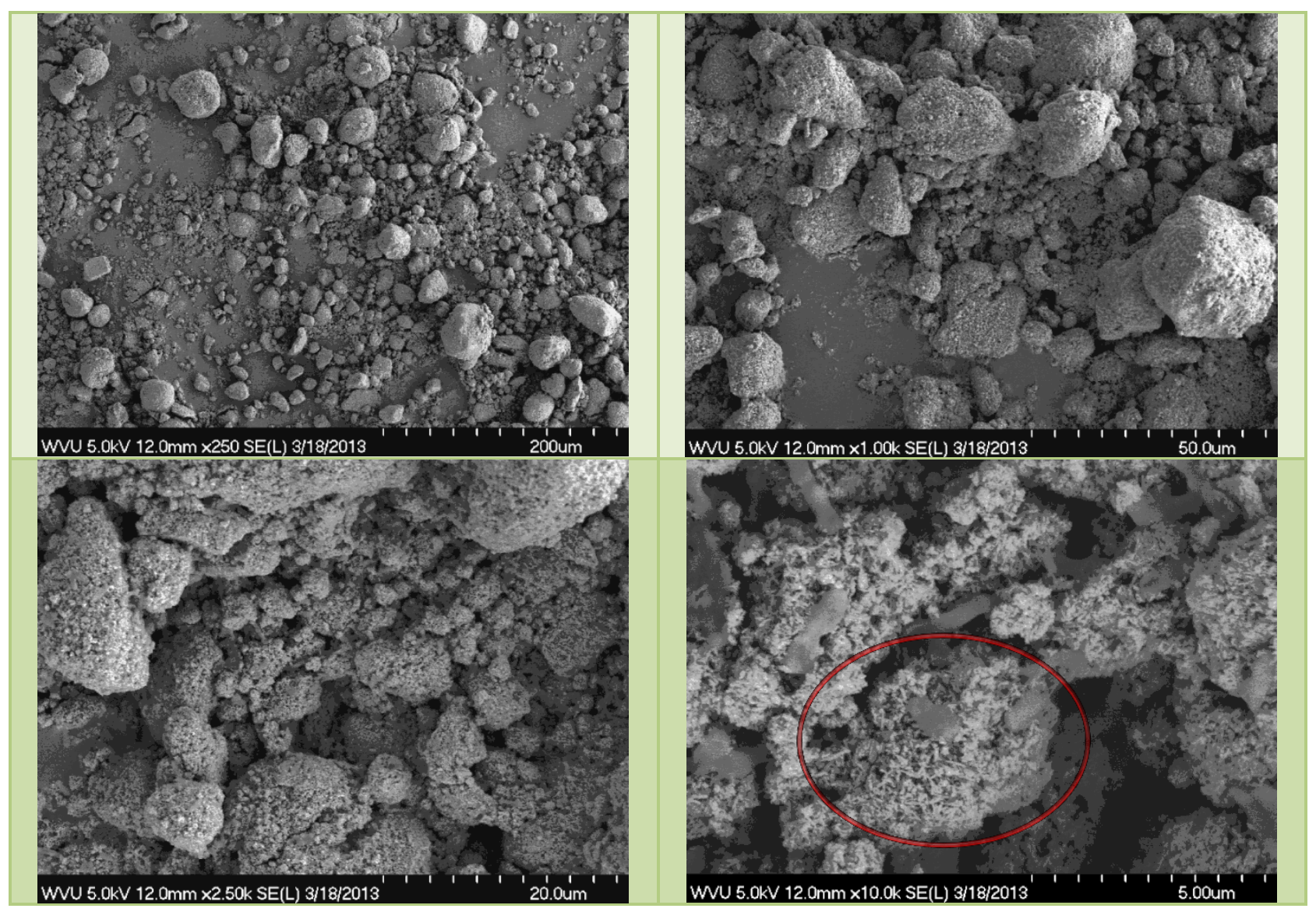

Figure 23 Typical Gram-negative BF, stages II and III, with unique three-dimensional architecture. (O) 


\section{Candida albicans Biofilm Phenotype - NaOCI Treatment}

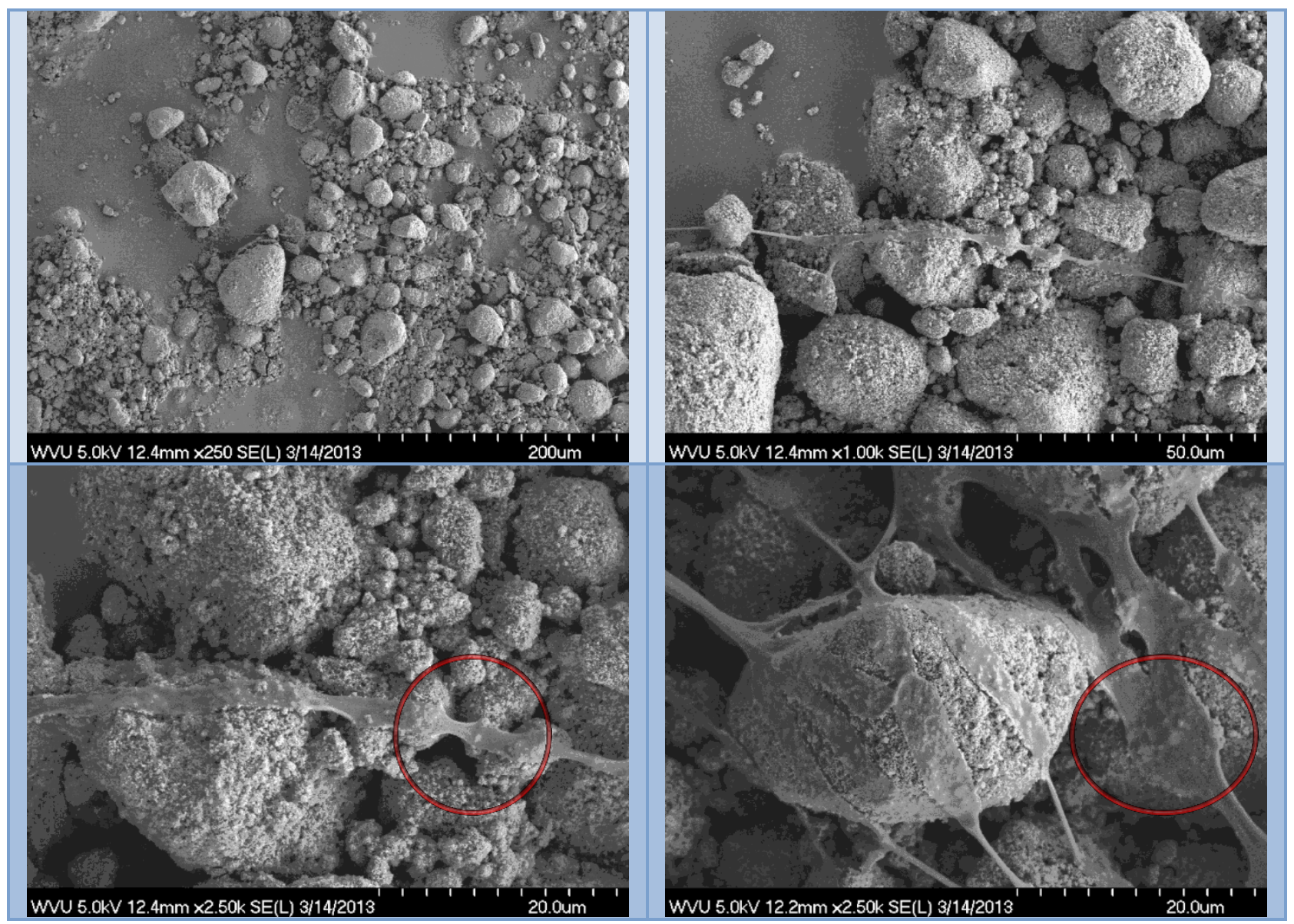

Figure 24 Altered stage III BF, with hyphal elements evident in 50 and $20 \mu \mathrm{m}$. The "coating effect" is apparent in Figure C and D of Candida hyphae. (O) 


\section{Candida albicans Biofilm Phenotype - DH Treatment}

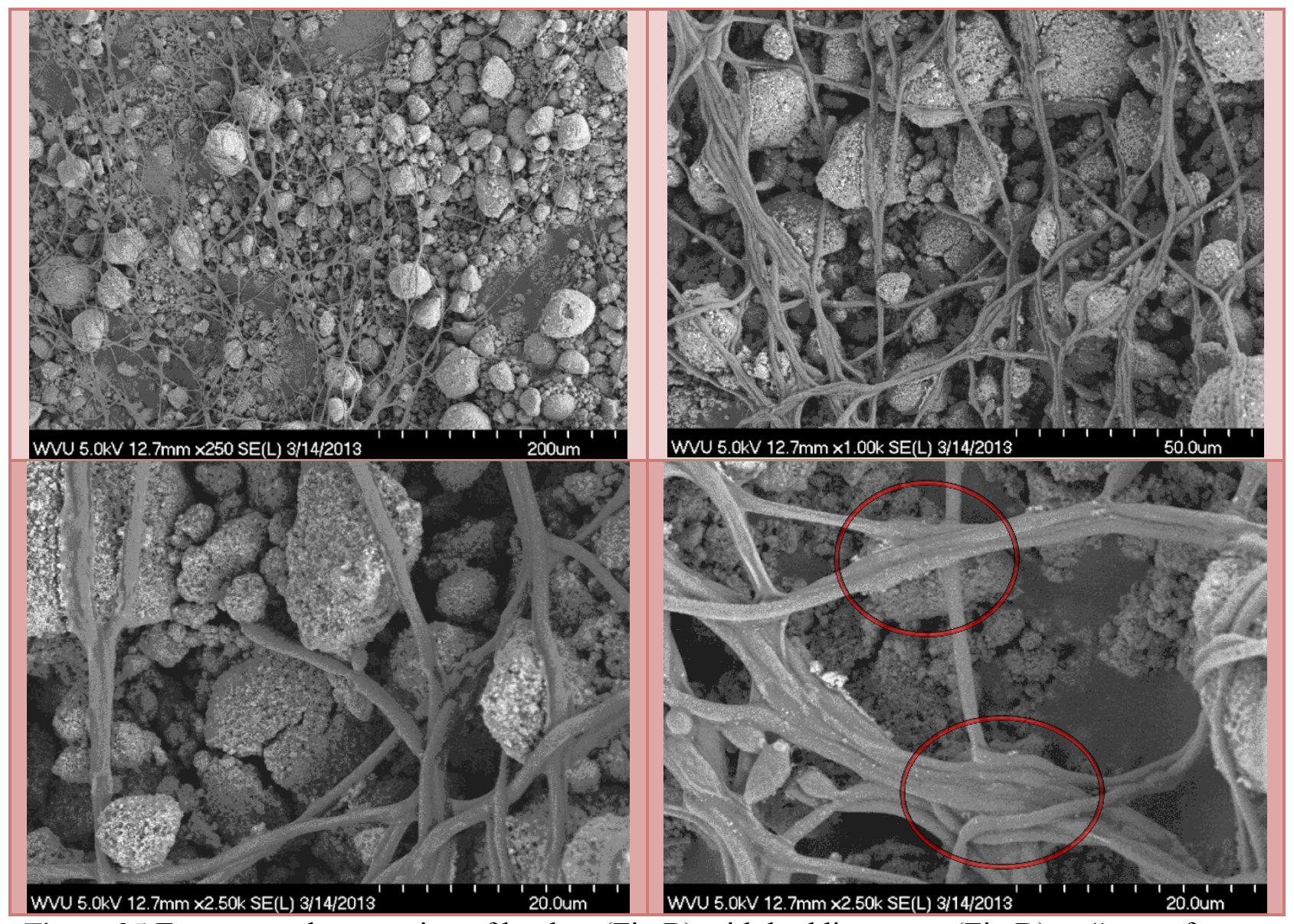

Figure 25 Exaggerated expression of hyphae (Fig B) with budding yeast (Fig D) as "area of interest". Note the multiple strands of hyphae elements adding to strength and potential "coaggregation" with Gram-positive microbes. (O) 


\section{Candida albicans Biofilm Phenotype - Saline Treatment}

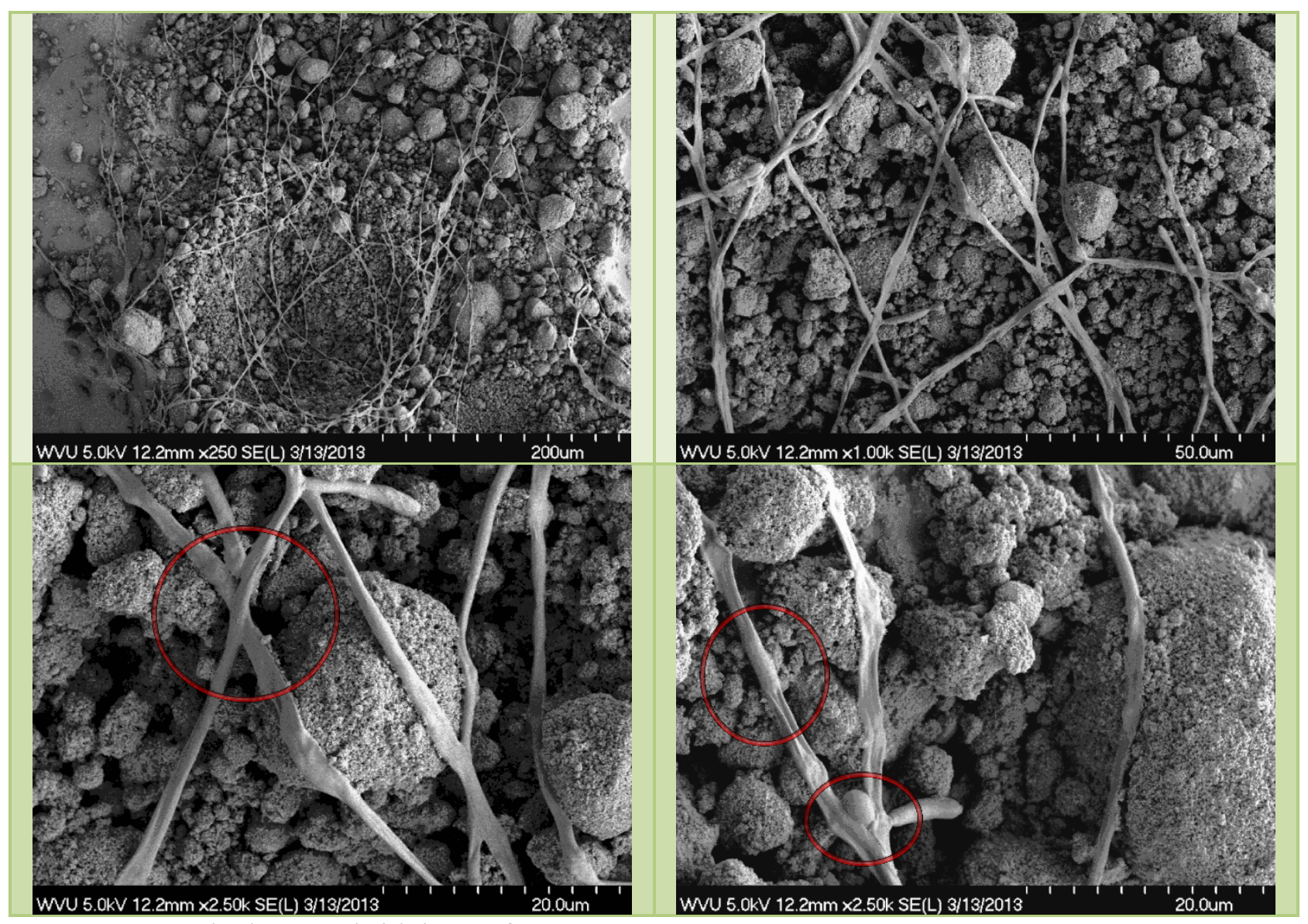

Figure 26 Typical "cross bridging" of Candida albicans in BF growth, stages III and IV. (O) 


\section{Chapter V}

\section{$\underline{\text { Discussion }}$}

The purpose of this study was to determine the effectiveness of delmopinol hydrochloride in removing an endodontic biofilm and to evaluate that performance in comparison to an already widely accepted endodontic irrigant, sodium hypochlorite. The experiment was specifically designed in an attempt to simulate the types of biofilm that may be encountered during root canal therapy.

The endodontic literature is presently seeing an influx of research regarding the understanding and role of biofilms in root canal failures. An endodontist's desire for successful root canal therapy in every case is a driving goal of the profession. The inability to obtain complete sterilization within the root canal system is a challenge for which clinicians and researchers alike are actively addressing. With the recent shift of focus to biofilms and the role they play in persistent infections, a biofilm targeting irrigant is now recognized as a necessary adjunct to endodontic treatment. Currently, the understanding and eradication of biofilms within the root canal system is an active and ongoing area of investigation in the endodontic literature. Biofilms have been shown to be present in cases with endodontic failures. (Carr 2009, Ricucci 2013) Ricucci has found this association particularly in cases with large periapical lesions showing no signs of healing; biofilms have also been associated with the presence of cysts. (Ricucci 2010) This investigation evaluated a potential irrigating solution's effect on an endodontic biofilm model, discussed any plausible applications in a clinical setting.

Staphylococcus aeurus, Pseudomonoas aeruginosa, and Candida albicans were selected as the microorganisms of interest based on the differentiation of gram positive and gram negative 
cell wall structures of the two prokaryotic microbes and the cell membrane structure of the one eukaryote. Figures 1 and 2, highlight the prokaryote and eukaryote structures. Gram stain of Staphylococcus aeurus and Pseudomonas aeruginosa show a significant size difference in the prokaryote and eukaryote cells. The biphasic properties of Candida albicans, growth as both a yeast phase and hyphal phase, increase the pathogenic potential, particularly the hyphal phase. Candida albicans is considered the "universal co-aggregate" and a major building block in transition from planktonic to biofilm architecture, making it an essential focus of interest when considering potential biofilm treatments.

Delmopinol hydrochloride has previously been proven to possess antibiofilm capabilities. Recent research in delmopinol hydrochloride's role in the oral cavity has demonstrated its ability to disrupt the biofilm known as plaque, leading to it being advertised as an alternative to periodontal rinses. With evidence of biofilm dissolution, delmopinol hydrochloride presented as a strong candidate for use as an endodontic irrigant when treating necrotic pulps and teeth with persistent periapical infections. Delmopinol hydrochloride's biofilm capability is well documented, so it is logical to investigate its effects on microorganisms in planktonic state prior to exploration of its effects on differing biofilm stages.

Initially, zones of inhibition were specifically chosen for this study to evaluate the antimicrobial capabilities of the studied irrigants. By first investigating this important quality of each irrigant, the determination of the value of pursuing further investigations was then decided. The irrigants were tested against each of the microorganisms in both planktonic and biofilm states. Both delmopinol hydrochloride and sodium hypochlorite demonstrated antimicrobial abilities, with sodium hypochlorite demonstrating significantly better antimicrobial properties against planktonic and biofilm models. Delmopinol hydrochloride did demonstrate capabilities 
in the biofilm form, but lacked performance on the Mueller Hinton plates. Previous studies have shown that the effectiveness of an antimicrobial reagent differs when an organism is found in a planktonic versus a biofilm state. (Ceri 1999) This difference in effectiveness may be offset by an increased exposure time, increased concentration of the irrigant, or introduction of supplemental aides, such as ultrasonic activation. (Townsend 2009)

The Calgary Biofilm Device (CBD) was chosen to closely simulate biofilm growth on a tooth-like structure. In dentistry, this model of hydroxyapatite coated pegs is used mostly in periodontal studies to demonstrate biofilm growth in the oral cavity. The CBD is advantageous to the study of biofilm growth due to the reproducibility and consistency of the biofilm formation, allowing for multiple antimicrobial solutions to be evaluated in a comparative manner. The CBD contains 96-pegs, all but those on the outside rim were coated with microorganisms in this study. The lack of a standardized method for evaluating biofilms within the endodontic literature currently inhibits the advancement in the understanding of the comparisons of existing and potential endodontic irrigants. (Stojicic 2013) Methods ranging from CBD, sterile dentine within orthodontic retainers, and hydroxyapatite discs coated with collagen have been utilized. (Ordinola-Zapata 2012, Stojicic 2013) However, an accepted, standardized protocol would greatly benefit the effort to develop an ideal irrigant. The microorganisms here were selected to show effectiveness against both prokaryotic and eukaryotic organisms in planktonic and biofilm stages.

The pegs from the CBD were treated with the irrigating solutions and designated for different methods of analysis. Pegs were stained with crystal violet to determine biofilm coverage using a Carl Zeiss microscope, pegs were sonicated to remove the residual biofilm to determine effectiveness through dilutions and counting of colony formations, and pegs were used 
for Scanning Electron Microscope images, capturing detail of biofilm stages with a Hitachi S4700 FE-SEM to a working distance of 12 millimeters.

The pegs designated for staining with crystal violet were viewed beneath a Carl Zeiss microscope and biofilm images captured. The results show biofilm coverage on all pegs with competing percentages of delmopinol hydrochloride and sodium hypochlorite. Sodium hypochlorite did show a significant increase in effectiveness on Candida albicans, a eucaryote.

The colony formation unit pegs were sonicated and a dilution with saline was made before transferring a sample to the Mueller Hinton plates for incubation and analysis. The results show successful formation of the microorganisms. Delmopinol hydrochloride revealed effectiveness against all three organisms tested. Sodium hypochlorite treatments resulted in no formation of biofilm removed from the pegs, while saline treatments revealed formation of the microbes did occur. This is indicative of the efficacy of sodium hypochlorite against the gram positive, gram negative and eukaryotic microorganisms, resulting in complete removal of the biofilm.

The pegs placed in formalin were viewed with a Hitachi S-4700 FE-Scanning Electron Microscope. The images revealed the presence of biofilm in stages II, III and IV. Delmopinol hydrochloride treatments resulted in alteration of the biofilm structures, including an interesting finding with Candida albicans, resulting in a reduction in the formation of yeast buds, and seemingly selecting for growth of hyphae. Sodium hypochlorite treatment also resulted in alterations in the architecture of the biofilm matrix, having more of a general effect of the structures than the investigatory irrigant. Saline had no effect on the biofilm, but revealed proper formation and confirmed no contamination. Neither delmopinol hydrochloride nor sodium 
hypochlorite treatments resulted in complete eradication of biofilm presence for either prokaryotes or eukaryote.

It is important to recognize that the four assay methods highlighted differed between delmopinol hydrochloride and sodium hypochlorite. Zones of inhibition were used as a preliminary data set, followed by the Calgary Biofilm Device, evaluating the pegs with crystal violet staining, sonication for colony forming units, and scanning electron microscope images. Each was able to show differences in efficacy of the investigated irrigants. Interestingly, the scanning electron microscope images provided the most unexpected information, showing differences in stage and structure, while demonstrating the effects of treatment. These images give a better overall understanding of the resilience and difficulty in removing of the biofilm, especially in stages II and III.

The null hypothesis was that delmopinol hydrochloride is not as effective on an endodontic biofilm when compared to sodium hypochlorite. The null hypothesis proves to be correct. Delmopinol hydrochloride was not as effective, but was still effective overall with similar efficacy for all three microbes tested. This suggests that the possibility of using delmopinol hydrochloride as an adjunct irrigation technique may be a plausible addition to the endodontic irrigation protocol, especially in necrotic cases or cases of persistent endodontic infections.

This is, however, a pilot study in an in vitro setting. Further research is required to realize the full potential of delmopinol hydrochloride as an endodontic irrigant. As stated previously, the CBD is used in dentistry predominately for periodontal research. Perhaps another biofilm model may be more likely to reveal more information about the prospective role 
this irrigant may play. Research into the response of the biofilm within the intricacies of the root canal system is also required. Additionally, this research did not investigate into the potential for a precipitate formation when the two irrigants are used in combination, neither the potential irrigants effect on the smear layer nor dentinal tubule penetration were examined. 


\section{Chapter VI}

\section{Conclusion}

The present study has demonstrated that, though effective against biofilm, delmopinol hydrochloride does not possess a more effective antimicrobial ability than sodium hypochlorite, rendering it of limited use in replacing sodium hypochlorite as the primary irrigation solution for root canal therapy. Delmopinol hydrochloride's inhibition of biofilm of both prokaryotes and eukaryotes, as demonstrated by the colony forming units and scanning electron microscope images, suggests that its effectiveness may be beneficial as an adjunct irrigant to sodium hypochlorite. The literature supports the antibiofilm capabilities of delmopinol hydrochloride in wound management, however, its application to endodontics needs further investigation. Further research needs to be conducted to thoroughly explore the efficacy of delmopinol hydrochloride within a root canal space. 


\section{$\underline{\text { References }}$}

Basrani BR, Manek S, Sodhi RNS, Fillery E, Manzur A. Interaction between sodium hypochlorite and chlorhexidine gluconate. J Endod 2007;33:966-969.

Baumgartner JC, Cuenin PR. Efficacy of several concentrations of sodium hypochlorite for root canal irrigation. J Endod 1992;18:605-612.

Baumgartner JC, Mader CL. A scanning electron microscopic evaluation of four root canal irrigation regimens. J Endod 1987;13:147-157.

Becking AG. Complications in the use of sodium hypochlorite during endodontic treatment. Report of three cases. Oral Surg 1991;71:346-348.

Beus C, Safavi K, Stratton J, Kaufman B. Comparison of the effect of two endodontic irrigation protocols on the elimination of bacteria from root canal system: A prospective, randomized clinical trial. J Endod 2012;38:1479-1483.

Burgemeister S, Decker EM, Weiger R, Brecx M. Bactericidal Effect of Delmopinol on Attached and Planktonic Streptococcus sanguinis Cells. Euro J of Oral Sci 2001;109:425-427.

Bystrom, A, Sundvist, G. Bacteriologic evaluation of the efficacy of mechanical root canal instrumentation in endodontic therapy. European Journal of Oral Sciences, 1981;89: 321-328.

Carr GB, Schwartz RS, Schaudinn C, Gorur A, Costerton JW. Ultrastructural examination of failed molar retreatment with secondary apical periodontitis: an examination of endodontic biofilms in an endodontic retreatment failure. J Endod 2009;35:1303-1309.

Ceri H, Olson ME, Stremick, C, Read RR, Morck D, Buret A. The Calgary Biofilm Device: New technology for rapid determination of antibiotic susceptibilities of bacterial biofilms. J Clin Microbiol 1999;37:1771-1776.

Chavez de Paz, L. Redefining the Persistent Infection in Root Canals: Possible Role of Biofilm Communities. J Endod 2007;33:652-662.

Ciucchi B, Khettabi M, Holz J. The effectiveness of different endodontic irrigation procedures on the removal of the smear layer: a scanning electron microscopic study. Inter Endod J 1989;22:21-28.

Clarke-Holke D, Drake D, Walton R, Rivera E, Guthmiller JM. Bacterial penetration through canals of endodontically treated teeth in the presence or absence of the smear layer. J Dent 2003;31:275-281. 
Clegg, MS, Vertucci FJ, Walker C, Belanger M, Britto LR. The Effect of Exposure to Irrigant Solutions on Apical Dentin Biofilms In Vitro. J Endod 2006;32:434-437.

Costerton JW, Stewart P, Greenberg EP. Bacterial Biofilms: A common cause of persistent infections. Science 1999;284:1318-1322.

Costerton JW, Veeh R, Shirtliff M, Pasmore M, Post C. The application of biofilm science to the study and control of chronic bacterial infections. J Clin Invest 2003;112:1466-1477.

Dakin HD. The antiseptic action of hypochlorites, the ancient history of the "new antiseptic". Brit Med J 1915;2:809.

Ehrich DG, Brian JD, Walker WA. Sodium hypochlorite accident: Inadvertent injection into the maxillary sinus. J Endod 1993;19:180-182.

Goldman LB, Goldman M, Kronman JH, Lin PS. The efficacy of several irrigating solutions for endodontics: a scanning electron microscopic study. Oral Surg 1981 52:197-204.

Grossman L, Meiman B. Solution of Pulp Tissue by Chemical Agents. J Am Dent A 1941;28:223.

Hand RE, Smith ML, Harrison JW. Analysis of the effect of dilution on the necrotic tissue dissolution property of sodium hypochlorite. J Endod 1978;4:60-64.

Hulsmann M, Hahn W. Complications during root canal irrigation. Int Endod J 2000;33:186-193.

Hulsmann M, Heckendorff M, Lennon A. Chelating agents in root canal treatment: Mode of action and indications for their use. Int Endod J 2003;36:810-830.

Kakehashi S, Stanley HR, Fitzgerald RJ. The effects of surgical exposures of dental pulps in germ-free and conventional laboratory rats. Oral Surg Oral Med Oral Pathol 1965;20:340-349.

Klinge B, Matsson L, Attstrom R, Edwardsson S, Sjodin T. Effect of local application of delmopinol hydrochloride on developing and early established supragingival plaque in humans. J Clin Perio 1996;23:542-547.

Krishnamurthy S, Sudhakaran S. Evaluation and prevention of the precipitate formed on interaction between sodium hypochlorite and chlorhexidine. J Endod 2010;36:1154-1157.

Lane J, Sjodin T. Prevention of bacterial contamination. US Patent 2008/0152688 A1. gents.

Lester K, Boyde A Scanning electron microscopic study of instrurnented, irrigated, and filled root canals. Br Dent J 1977;143:359-366. 
McComb D, Smith D. A preliminary scanning electron microscopic study of root canals after endodontic procedures. J Endod 1975;7:238-242.

Metzger Z, Teperovich E, Cohen R, Zary R, Paque F, Hulsmann M. The self-adjusting file (SAF). Part 3: Removal of debris and smear layer - a scanning electron microscope study. J Endod 2010;36:697-702.

Mohammadi Z, Abbott PV. The properties and applications of chlorhexidine in endodontics. Inter Endod J 2009;42:288-302.

Nair PNR. Light and electron microscopic studies of root canal flora and periapical lesions. J Endod 1987;13:29-39.

Oksan T, Aktener BO, Sen BH, Tezel H. The penetration of root canal sealers into dentinal tubules. A scanning electron microscopy study. Inter Endod J 1993;26:301-305.

Ordinola-Zapata R, Bramante CM, Cavenago B, Graeff MS, Gomes de Moraes I, Marciano M, Duarte MA. Antimicrobial effect of endodontic solutions used as final irrigants on a dentine biofilm model. Inter Endod J 2012;45:162-168.

Peters OA. Current challenges and concepts in the preparation of root canal systems: a review. J Endod 2004;35:559-567.

Ricucci D, Loghin S, Siqueira JF. Exuberant biofilm infection in a lateral canal as the cause of short-term endodontic treatment failure: report of a case. J Endod 2013;39:712-718.

Ricucci D, Siqueira JF. Biofilms and apical periodontitis: study of prevalence and association with clinical and histopathologic findings. J Endod 2010;36:1277-1288.

Schilder H. Filling root canals in three dimensions. Dental Clinics of North America 1967;723744.

Senia ES, Marshall FJ, Rosen S. The solvent action of sodium hypochlorite on pulp tissue of extracted teeth. Oral Surg Oral Med Oral Pathol 1971;31:96-103.

Shuping GB, Orstavik D, Sigurdsson A, Trope M. Reduction of intracanal bacteria using nickeltitanium rotary instrumentation and various medications. J Endod 2000;26:751-755.

Simonsson T, Hvid EB, Rundegren J, Edwardsson S. Effect of delmopinol on in vitro dental plaque formation, bacterial acid production and the number of microorganisms in human saliva. Oral Micro and Immun 1991;6:305-309.

Siqueira Jr. Aetiology of root canal treatment failure: why well-treated teeth can fail; A Review. Int Endod J 2001;34:1-10. 
Spangberg L, Langeland K. Biologic effects of dental materials: 1-toxicity of root canal filling materials on HeLa cells in vitro. Oral Surg Oral Med Oral Pathol 1973;35:402-414.

Stewart PS, Costerton JW. Antibiotic resistance of bacteria in biofilms. The Lancet 2001;358:9276:135-138.

Stojicic S, Shen Y, Haapasalo, M. Effect of the source of biofilm bacteria, level of biofilm maturation, and type of disinfecting agent on the susceptibility of biofilm bacteria to antibacterial agents. J Endod 2013;39:473-477.

Stoodley P, Sauer K, Davies DG, Costerton JW. Biofilms as complex differentiated communities. Annu Rev Microbiol 2002;56:187-209.

Townsend C, Maki J. An in vitro comparison of new irrigation and agitation techniques to ultrasonic agitation in removing bacteria from a simulated root canal. J Endod 2009;35:10401043.

Tronstad L, Barnett F, Cervone F. Periapical bacterial plaque in refractory to endodontic treatment. Endod Dent Traumatol 1990;6:73-77.

Vertucci FJ. Root canal anatomy of the human permanent teeth. Oral Surg Oral Med Oral Pathol 1984;58:589-599.

Vianna ME, Gomes BPFA, Bellocchio B, Zaia AA, Ferraz CCR, de Souza-Filho FJ. In vitro evaluation of the antimicrobial activity of chlorhexidine and sodium hypochlorite. OOOOE 2004;97:79-84.

Violich DR, Chandler NP. The smear layer in endodontics - a review. Inter Endod J. 2010;43:215 .

Walker A. Definite and dependable therapy for pulpless teeth. JADA 1936;23:1418-1424.

White RR, Goldman M, Sun Lin P. The influence of the smeared layer upon dentinal tubule penetration by plastic filling materials. J Endod 1984;10:558-562.

Wilson. M. 1996. Susceptibility of oral bacterial biofilms to antimicrobial agents. J. Med. Microbiol. 44:79-87.

Zehnder M. Root canal irrigants. J Endod 2006;32:389-398 